\title{
SOCIAL STRUCTURE, EDUCATIONAL ATTAINMENT AND ADMISSION TO LAW SCHOOL
}

\author{
ALEX ZIEGERT*
}

\section{INTRODUCTION $^{1}$}

"From the moment you are born, ...", a recent TV advertisement tells us, “... the odds are stacked against you!”. The advertisement then goes on to demonstrate how minimal the chances are to incur certain favourable life-events. It suggests that, rather than trying hard, it is better to play the lottery as a way of overcoming the adversities of everyday life. However doubtful the actuarial calculations may be which are used in the advertisement, it makes a forceful point: what we expect to be, and what - in a democratic society - is promised to be, apparent equality of opportunities turns out as a maze of barriers, dead-ends and capricious events. What the lottery advertisement implies, but what the liberalist democratic formula fails to tell us generally, is that the equal chances provided by the social life of any society are not only as bad as, but in fact worse, than chances provided by a lottery. Different from the lottery, the "odds" in real life are systematically "loaded when equal access is attempted to health, wealth, power and status, or to whatever seems worth achieving in a given society. What appears to be chance, or at best fate and providence, is evidently the invisible hand of social structure, tipping the scales consistently in the direction of how that structure itself operates at any given time in the life of an individual from the moment the individual is born.

This observation is, of course, hardly original. However, it is 
important to keep it in mind when one wants to assess the practices of admitting access to tertiary education - a resource in all modem societies - and when one wants to design policies which are aimed at reforming the access to law schools - a formidable resource in all societies which follow the common law tradition. Viewed from the aspect of the complex and pervasive historically entrenched social structure and social processes, to change admission practices effectively is an awesome task. Admission policies which are advocated as "new" can be safely assumed to be merely the administration of more of the same unless enough leverage can be mobilised to unsettle the systematic bias of social structure and to neutralise some of the thoroughly debilitating effects of its invisible hand. Obviously, to attain such leverage is beyond the scope of individual universities and/or their law faculties, and it is outside the work practices which are employed in the admission of students. We must assume that whatever universities can or will do necessarily amounts to not much more than tinkering with the systematic bias of social structure.

There is now compelling evidence that this is in fact the only result which universities have achieved in a fairly long history of admission policy reforms in the tertiary education sector in Australia. There is also increasing consensual knowledge ${ }^{2}$ that the even more comprehensive and better coordinated actions and programmes on state or national government level, which were designed to affect the social mix of undergraduates in Australia and overseas had no, or only a limited effect. ${ }^{3}$ Often, the small effect achieved by incisive single-measure government intervention ${ }^{4}$ or by broad equal opportunity policies is counteracted by subsequent changes in admission policies ${ }^{5}$ which in turn make access to higher education even more highly competitive. Any gains made by these policies are whittled away by the social forces at work on a deeper and more complex level of a given society. ${ }^{6}$

It is important to note, however, that this bleak picture changes somewhat where specific target groups are concerned. Here more narrowly tailored government programmes can be shown to be reasonably successful. ${ }^{7}$ Special programmes of this kind remain promising but are, by definition, limited in their outcomes.

Finally, a third and different case in the history of admission practices in educational organisations in general and, especially, in 
the tertiary education sector, is the case of women. It provides us with the evidence that the dynamics of the invisible hand of social structure can be forced over time even if ever so slightly. Women, coming from a position of practical exclusion from higher education, have achieved, at least nominally, equal access to higher education with men, even if, as yet, actual admission practices are still quite patchy. ${ }^{8}$ As the following discussion will show, this more complex change in admission practices but, more importantly, in educational attitudes towards girls and women generally, has had and still has crucial consequences for structural change in a given society. This potential for change is related to the pivotal role women have in societies as mothers who are, rather than fathers, effectively in charge of the socialisation of their children. This is generally the case in all societies but plays a particularly important role in the educational programmes of societies which are on the way to become modern, industrial societies and possibly postmodem societies. ${ }^{9}$ It appears, then, that the educational attainment of mothers is one of the most powerful single predictor variables for structural change and for intergenerational transmission in societies. A review of admission policies has to address this observation.

In view of the complex operation of social structure and social process, and their combined effects on the work practices of educational organisations on all levels (family, primary education, secondary education, and tertiary education), a review of admission practices cannot be content to assess admission to law school as a single, independent event but must attempt to link this event to the socio-historical context in which it occurs and in which a particular educational organisation operates. This link provides the parameters for educational operations on all levels, from childhood to adulthood, on which selection occurs. The following discussion is a report of an attempt to draw such a link. This attempt is limited by the specific objectives of the task set for the researchers. ${ }^{10}$ However, neither the explorative nature of such a study nor its necessary limitations should preclude that the evaluation and discussion of results are attempted with a substantial and explicit connection between theory and research. ${ }^{11}$ The study, as presented in this report, attempts to demonstrate such a connection. It introduces a general model of the selective dynamics of social 
structure and social process as they can be seen to bear on educational operations, including admission practices, and as they can be shown to apply to New South Wales and to the work practices of the Faculty of Law of the University of Sydney in particular. This model is based on the theory of operationally closed systems ${ }^{12}$ described in section 2 . Such a model informs us what kind of data are needed and how they can be collected (described in section 3) and it directs the way in which the collected empirical material can be understood (interpreted) and presented in the following discussion (section 4). Though such an approach uses the collected data to the best knowledge of the researchers, it is obviously still not the full story of admission to law school.

\section{THE PRACTICE OF LAW STUDENT SELECTION IN NEW SOUTH WALES - A THEORETICAL MODEL}

The concept of law school intake (admission), as envisaged here, starts from the assumption of a highly stratified concatenation of selection processes which affect every individual student on a number of steps in the student's life-career. The result of these selection processes is effectively, as far as our law students are concerned, that they are eventually accepted as law students: they have "made it". However, seen against the background of the population at large, the chances of a new-born child to be eventually admitted to law school are rather remote.

We find, then, a systematic funnelling process represented in the life-careers of law-students as compared with the life-careers of young adults at large. This process is made up by a great number of multi-level selection processes which, in the sociological sense, are constituted by the interplay of socialisation and education. ${ }^{13}$ This interplay is orchestrated by social structure ${ }^{14}$ over time, both in the Australian society at large and in the society of NSW in particular. The picture which we gain from this sociological view on law student selection as practised by a particular law school (Sydney University Law School) appears to be that of a funnel which has numerous filter levels. Each of these filters allows for only a minority of individuals to pass through to subsequent levels and retains the rest. Evidently, those individuals who pass each level to the next one possess particular (highly selected) personal 
characteristics and they share these characteristics with all those others who have also passed; and, the more filters these individuals pass, the more those who pass share personal characteristics with each other. ${ }^{15}$ Seen from the vantage point of the eventually successful admission to law school, and with hindsight, all law students share the experience of such a rather long, and in fact when compared with other university studies - one of the longest possible, educational career-paths. The high homogeneity of the personal profiles of the students in this group should not come as a surprise. The most remarkable feature of this homogeneous group is the over-representation of individuals who come from families with high socio-economic status in a given society, and who have had - on their long march through the education system sufficient time and specific support in these family environments to learn how to become educated. This feature becomes more prominent with each step on the career-path in the educational system. In short, our model suggests that institutionalised education is not a simple hand-out of knowledge to particular individuals but rather a series of selective operations by families, educational organisations and the economic system to which individuals adjust skilfully by socialisation. The overall outcome of education is that a specific group of individuals acquire a particular set of social skills which affect the way in which those individuals operate their cognitive manoeuvres of self-concept maintenance in order to achieve individually perceived goals which are at the socio-cultural and socio-economic disposition of society at large.

A comprehensive account of the complexity of the historical conditions for educational outcomes in NSW is beyond the scope of our study but such historical conditioning must be kept in mind. It refers to a small, geographically relatively isolated society which is demographically concentrated in the State capital, resulting in an extremely low, degree of mobility but a high degree of interaction between the local elites. This historical framework of a small society in a large geographical space is basically a provincial one and one which is characterised by economic vulnerability. ${ }^{16}$ Here, the society needs to respond to wider international developments through the adjustive operations of the economic and education systems. Historically, it appears that in Australia and NSW the education system has been the more open and resilient one and that 
the economic system has been the more, protectively, closed and vulnerable one. Thus, while Australia has never developed a strong secondary, industrial sector - and in this sense has never become an industrial society in the full (socio-economic) sense of the term - it has become a modern developed society by the responsiveness of its highly differentiated education system. This education system provides the necessary cultural capital to drive a relatively strong tertiary industry (services) sector in a vibrant multicultural environment. In Australia, as anywhere else in modern Western societies, the crucial measure for development, then, is the capacity to relate the operations of the economic system and of the education system meaningfully to each other. Such a meaningful relationship between the operations of different systems can be understood in the terms of structural coupling. ${ }^{17}$ This means, in the case of a structural coupling of the economic and education systems. that the operations in each system condition each other through the use of references to certification (certificates, degrees and diplomas). The reference made to certification by both the education system and the economic system means that access to economic resources (positions of occupational status and/or wealth) in NSW, as anywhere else in modem societies, depends increasingly, and often exclusively, on the attainment of high levels of formal education rather than on a traditional recognition of practical skills through non-certified educational operations in the economic system itself (for example by training "in house” or "on the job”). By issuing certificates and by a recognition of issued certificates, the economic and the education systems condition each other externally and they co-ordinate their respective autonomous internal operations by referring to, and occasionally quarrelling over ${ }^{18}$ certificates. 


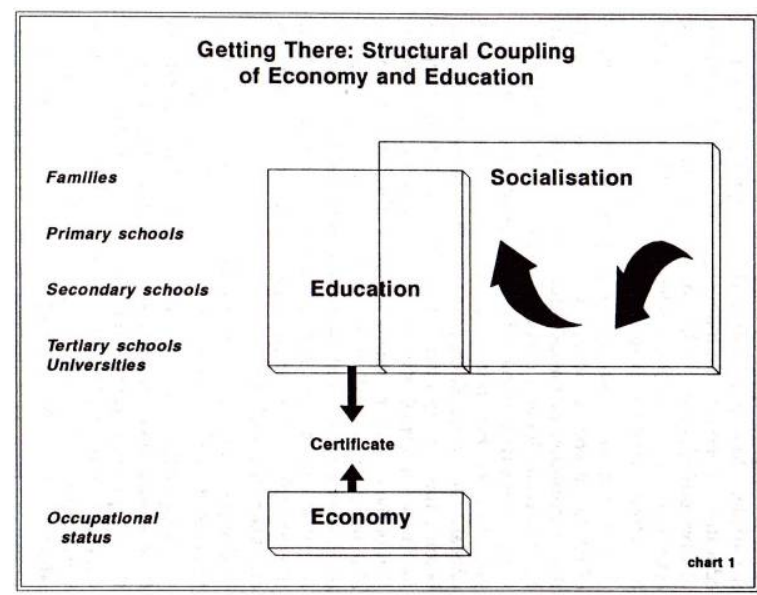

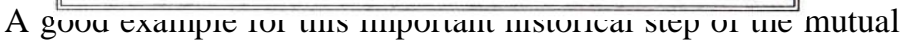
recognition of the economic and educational systems in the structural coupling through references to certification is the change in the approach to recruitment for the legal profession in Australia and in NSW. Here, selection of recruits to the legal profession has turned from a regime of apprenticeship ${ }^{19}$ and in-house approbation in the position of the articled clerk to a nearly exclusive regime of university education or tertiary-education-styled education in colleges of advanced education, college of law, joint admission board courses and examinations, modelled after university courses and administered by university staff.

The complex pattern of change by mutual connectedness of education and economics has had a profound effect on the organisation of formal education. Educational careers have become longer, curricula more complex and more varied. Moreover, formal education has become more comprehensive for the entire population, and in turn, access to educational organisations, especially their higher levels, has become more competitive. ${ }^{20}$ With every additional rung in the ladder of formal education, that is, a further differentiation of the education system, numbers of intake increase but also selectivity overall increases. Rather than to equip individuals for coping with modem society, this process of differentiation has the pervasive effect of sequestering (classifying) — often irretrievably — the certified winners and losers in social life. 


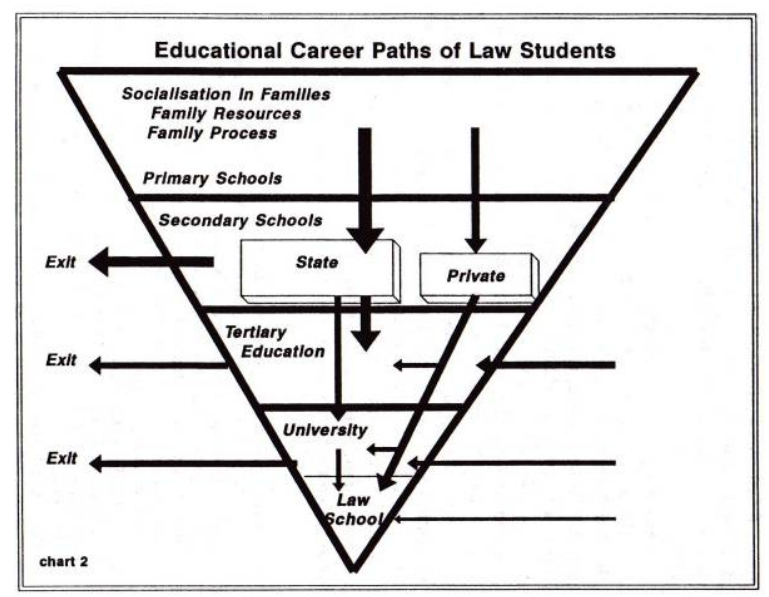

Conveniently simplified, we can distinguish five major levels of the educational careers of law students in NSW The socialisation in a family home and in institutions (like kindergarten, primary schools) supporting socialisation in primary groups (families). On this basic level, education is not highly formalised. This lack of formalisation, accounts for both the strength and the failures of education on this level. A major problem is that there is no formal exit from the educational system on this level; educational success is exclusively dependent on the socialisation processes which go on in the privacy of family homes and/or in other primary group environments. ${ }^{21}$ Such family or primary group performances are, in turn, crucially dependent on the organisational quality of the unit, measured in terms of their resources (e.g. socio-economic status and educational attainment of members) and of the on-going processes in the unit for example supportiveness, communication, interaction, and liaison with external environment. Resources and process together provide for the human development and for the socialisation of social competence of children and adolescents, ${ }^{22}$ but also of the adults in such units.

Evidently, educational careers are formed on this level; omissions and commissions perpetrated on individuals on this level are highly formative for the protection and maintenance of selfconcept and so for the pathways which the life-course of individuals will take. ${ }^{23}$ Because socialisation does not allow for exits while education does, ${ }^{24}$ the most distressing feature of education at this level of low formalisation is that the mode of 
selection of the education system, and particularly, a number of specific "exits" from the education system, are not easily visible and/or are not conceptualised as such. Rather, classifications of "success", "failure", and "dropping out" are hiding here in the private niches of family life as so-called apathy, disinterest, retardation, unruliness, dyslexia, or as diagnosed psychosomatic, neurotic and psychotic disorders. Nevertheless, the labels with which are assigned to individuals here, stick with the respective individuals through informing their self concepts; they learn to see themselves as failures in an early age, and this will be the most distinct feature of the life-careers of such individuals.

The socialisation and education in secondary schools. In becoming more formalised, the selectiveness of the education system becomes more conspicuous. With this higher degree of organisational formalisation, also exits from the educational system are formalised (certified) on this level. Internally, the higher degree of formalisation allows for more differentiation (specialisation) of the system; it can fast-track some individuals for further advancement and discourage others from staying on. Students emerge from secondary schools as firmly classified candidates for economic roles. However, the selective effect of the official classification of educational attainment is also related to the way in which it is valued by the respective individual on the base of personal and family values. Such values allow, for instance, to view earning money forming a family or just dropping out of school as superior to the long term goal of reaching high levels of educational attainment with diffuse career perspectives and distant earning capacities.

A special feature of the education system in NSW on this level is the segmented operation of public (state) and private schools, and especially secondary schools. ${ }^{25}$ This segmentation of the education system disperses scarce public resources further, and it increases the selectiveness of the education system on this level by introducing further rungs. While state schools have to cope with a majority of mandatory students in often adverse educative environments, private schools can capitalise for their educational operations on the formative effects of family resources and family process provided by those students who are set to have the longest educational career-paths: students from private schools spend the 
longest time of all students in the state in the education system.

Our model suggests, then, that while state secondary schools have large numbers of students, they also have large numbers of "drop outs" and of students who will leave the education system as certified leavers on this level (year 10 school certificate). Comparatively few of these students will stay on in the education system to go to university and even fewer will be admitted to law school. In contrast, private schools deal only with small but highly selected populations. Only very few students here will exit the education system before reaching university, and many of them will be admitted to law school.

The socialisation and education in tertiary education institutions. With the increased differentiation of the economic system, the importance of the education system grows and the pressure on the internal differentiation of universities intensifies. The result is a further spread of university sub-systems (schools, faculties, departments, amalgamations) and their competition for resources by further differentiation of certification through more specialised degrees or diplomas.

With the increased internal differentiation of universities and tertiary education institutions, the tertiary level also becomes an important re-entry level for many individuals who have left the education system at earlier stages and who decide to upgrade their chances for a better access to the economic system by higher levels of educational attainment.

As far as the present practice of law school admission is concerned, this group of re-entry students have to compete with the systemicly better positioned "educational stayers" from the secondary schools, and especially those from the private secondary schools.

The socialisation and education in universities. The demand for highest level education certification has expanded the scope and variety of university activities. This has meant a further differentiation of certificate levels in grades of degrees, number of degree levels, and the specialisation of degrees and diplomas. Each of these differentiation levels, in turn, must be seen to function predominantly as a selective rung in the ladder of educational careers. While the educational value of these differentiations of certification remains doubtful, ${ }^{26}$ provide clearly the bonus of 
additional or cumulative certification for individuals and organisations. With that, they also provide a further step to prevent or facilitate access to law school in those cases where direct access from secondary school is not possible.

The socialisation and education in law schools. In spite of the, then rather late, incorporation of legal education in universities, the law school in the Anglo-American setting has maintained a separateness from university operations in general. This applies also to the modem version of Anglo- American law school teaching and research under, oddly enough, the auspices of interdisciplinarity and contextuality. No other field of academic endeavour maintains so tenaciously institutional generality and is so poorly organisationally specialised (differentiated) as legal education at law school. This peculiar historical role of law schools refers to a more specific and direct structural coupling with the economic system which can be found in the role that the legal profession plays in the history of common law. This direct link between the legal profession and law school overrides, in many respects, the structural coupling of education and economics which applies generally to universities and it determines the higher selectivity of law schools as compared with admission to university in general.

This higher selectivity of law schools is expressed in features such as more restricted admission quota, special provisions for combined degrees and an implicit tendency toward graduate schools which are not present in other university faculties. ${ }^{27}$

In this crucial aspect of highest educational selectivity, then, law schools exhibit the same features as private secondary schools. Both, private secondary schools and law schools can present the unique structural position which they hold in the education system as "producing excellence".

Their higher selectivity allows them to capitalise on refined selection procedures and on elaborate educational classification schemes. These classification schemes mandate longer than average educational career paths and strong family commitments to those students who are set up to stay on those longer career paths. It is, then, not surprising to find in law schools predominantly those students who also populate the private secondary schools.

Taken together, all rungs in the ladder to educational attainment 
have the effect that the educational career which leads to a first law degree is one of the longest in the educational system. In turn, the student population so selected is, in the end, one of the most homogeneous student populations in universities. ${ }^{28}$ However, this homogeneity does not necessarily relate exclusively to socioeconomic (class) criteria or academic achievement criteria (high HSC/TER) scores. Rather our model suggests that the homogeneity of the law student population at Sydney University is the result of the perseverance on a rather long educational path as effected by a combination of favourable family background variables, among them also the socio-economic status of families. In this respect, addressing only the warped social mix of the law student population means to overlook the more complex historical problem why some families promote the acquisition of cultural capital in their children while others do not and how the pathways of social mobility may look like which lead from being born in the latter family- type to constituting a family of the former family-type as an adult who can intergenerationally transmit the value of education to her children.

The research project, commissioned by the Faculty of Law of the University of Sydney, had the objective of assessing the effects of current admission practices as reflected in the profile of admitted law students. Based on the model of law student selection discussed above, a longitudinal study would have been the preferred approach. Such a longitudinal assessment could have encompassed all stages of the selection process, including the formative family processes and also the exits from the selection process of those students who either do not seek or who fail to gain entry to law school. However, due to time constraints this was not a feasible option. Instead and by convenience, our research concentrates on the later stages of the selection process and relies exclusively on the self-reports of law students. The deficiencies which result from this approach will be discussed in the next section.

\section{METHODOLOGY}

The collection of data for this study was conducted in two phases: ${ }^{29}$

1 A survey by questionnaire ${ }^{30}$ of a sample of first year law students $(n=159)$ and of a sample of advanced (penultimate or 
last year) law students ( $n=121)$, having regard to their sociodemographic profile, their educational career patterns, their personal assessment of the existing admission practices, and the experienced conditions of studying at the law school (quantitative research);

2 An ethnographic interview with a random sample of last year students $(n=33),{ }^{31}$ having regard to their experience of the educational careers, their studies at law school and of the outcomes of the admission practices of the law school (qualitative research).

The rationale for constituting the samples in this way was to survey two substantially large student populations who differ with respect to:

- their educational career pattern (that is, students with longer law school experience and possibly different forms of entry compared with those who have just entered law school directly from high school) and,

- the year when they enroled in law. Here, a group of students who were admitted in 1990 is compared with a group of students who were enroled in the period from 1983 to 1986 (60\% of this sample) or earlier. These samples were drawn conveniently from particular compulsory law school claws (first year law: Legal Institutions; penultimate and/or last year: Jurisprudence). They do not constitute a random sample of first and last year law students respectively in the strict sense but provide two valid samples of students who have been subjected to different selection practices of the law school. As a result, the different outcomes of the admission practices that constituted these populations are evident. The sample of the first year law students is made up by students who were admitted directly to one of the combined law degrees (BA/LLB, BEc/LCB, $\mathrm{BSc} / \mathrm{LLS}$ ) on the basis of their high school results. The sample of older law students is made up by students with a mare varied mix of admission careers (direct from high school, graduate students, students with transfer from other degrees or other law schools; see Table 1). In order to label these different groups of law students conveniently for the presentation of results, we refer to them as "first year" students and "final year" students respectively but their different configuration patterns should be 
kept in mind.

Table 1: Students Who Entered Law as a Graduate

\begin{tabular}{|lcc|}
\hline SQ 7.2 WHAT WAS MAJOR AREA OF STUDY & \\
\hline & First Year & Final Year \\
Arts & - & 20.5 \\
Science & - & 5.2 \\
Economics & - & 4.3 \\
Not Appl. & 100.0 & 70.1 \\
N & 159.0 & 117.0 \\
\hline
\end{tabular}

A further critical methodological point in the study is the use of student's self-reports rather than, for instance, observational data. Self-reports create the methodological bias that findings reflect current perceptions of self of students, at the point of time of the report, rather than accurate ("objective") records of past events in the educational careers of students. ${ }^{32}$ It appears, however, that this general problem in social science research is of little consequence in our study. On the one hand, faulty or falsified ("beautified") recall by students must be considered to be minimal as far as concrete, biographical data and objective (officially recorded) events of their family backgrounds (occupational status of parents, educational attainment of parents) and educational careers (school type, degree type) are concerned. On the other hand, the reporting of students' (perceived) self-concepts was intended because selfreports are the only access to the assessment of the experience of students. This approach is further accentuated by the complementary use of qualitative research methods. In this approach, interviews with largely open and unstructured questions were used which allowed students to elaborate on personal experiences and individual viewpoints.

\section{FINDINGS AND DISCUSSION}

The methodological dilemma that our study does not reflect adequately on processes which precede admission to law school, is 
particularly acute with regard to the early and most formative childhood experiences of law students. Selective processes are here set in the environment of face-to-face relations organised in primary groups, that is, mostly by family relations and, to a lesser extent and only complementary, by peer group relations. Significantly, even the law students themselves refer only rarely to these early years when talking more freely about their educational careers in the interviews. However, the effects of some fairly reliable standard variables of socialisation research $^{33}$ can be discussed in the light of the results of our survey. These variables account for the distinction between family resources (educational attainment levels of parents, occupational status and work situation of parents, income levels but also network support, access to infrastructure, access to dominant culture through competence in language and culturally highly valued behavioural patterns) and family process (bonding between family members, communication, support, power/authority structures). These different sets of variables focus on interrelated but specifically differentiated outcomes of primary group socialisation. The relationship between the underlying family operations measured by the two sets of variables is, as a rule but not invariably accumulative throughout family histories, either in a positive form, that is, as benign "upward" loops, or in a negative form, that is, as vicious "downward loops. Furthermore, these family operations are also, through intergenerational transmission, accumulative through generations. ${ }^{34}$ This means that, depending on the quality of family resources and processes, individuals growing up in respective families are more or less resourceful themselves. Additionally, there is a significant probability that a person may engage in a stable interpersonal relationship, and finally form a new family with a person who commands similar levels of resourcefulness as that person. This results in the prevalent homogamic patterns where individuals with similar levels, for instance, of educational attainment or occupational status pool whatever resources they command, and where this leads to even more pronounced differences of family coping, including child rearing, between different families. 


\section{FAMILY RESOURCES}

It is evident from our findings that the law students in our samples come largely from families which have been highly successful in the accumulation of cultural and economic capital. ${ }^{35}$ Fathers and mothers of law students have overall, and by any count, a far higher occupational status and a higher level of educational attainment than fathers and mothers in the population of Australia at large (compare Tables 2 and 3, levels of parental educational attainment, with Tables 4 and 5). So, the high proportion of fathers of law students with professional occupational status (about 25\%) compares with only $14 \%$ of men with that status in the Australian population at large. ${ }^{36}$ Conversely, only $9 \%$ of the fathers of law students and $18 \%$ of the mothers are reported to have the status of clerk or worker, compared with $44 \%$ and $69 \%$ of men and women in Australia overall who are reported to have that occupational status. Likewise, roughly $50 \%$ of the law students report that their fathers have attained a university degree, and nearly the same proportion of mothers who hold such a degree (49\%) is supported by the first year intake (19901, while only $11 \%$ of the men and $8 \%$ of the women in work in Australia are registered in the official statistics with such a level of educational attainment. ${ }^{37}$ Conversely, $26 \%$ and $24 \%$ of the law students report that their fathers and mothers have attained an educational level which is less than a Higher School Certificate, while $37 \%$ of the men and $43 \%$ of the women in work in Australia are reported to have attained that level. $^{38}$

In the very few cases where students have achieved admission to the law school in spite of the fact that lower levels of both occupational status and educational attainment of parents are reported, the nominal disadvantage in these families is probably balanced by favourable family process, for instance, an effective network of good relations between the members or the family which results in a highly supportive and committed family environment. This is discussed further in section 4.3.

Occupational Status and Level of educational attainment of Parents. Two family-background variables are most clearly related to structural advantage in modem Australian society. These are the father's occupational status and the mother's level of educational 
attainment. Findings related to these variables in our students' selfreports support the observation, made earlier, about resourceful family configurations in the law student sample. Mothers in these families are reported - when compared to their male partners - to have achieved similarly high or even higher, but rarely considerably lower level of educational attainment, and a lower occupational status than that of their male partners. Conversely, fathers in these families are reported to have achieved a higher occupational status - compared to their female partners - and a similarly high but frequently also a lower level of educational attainment than that of their female partners. The result of such configurations are highly favourable family environments and it is this high level of the educational attainment of their mothers combined with the high occupational status of their fathers which appears to be the crucial element in the life-careers of those students who are eventually admitted to law school. 
Table 2: Father's Occupation

\begin{tabular}{|lcc|}
\hline SQ 10 FATHER'S OCCUPATION & \\
\hline & First Year & Final Year \\
Upper Professional & 26.1 & 24.8 \\
Low Professional & 3.2 & 4.3 \\
Upper Services & 19.1 & 19.7 \\
Low Services & 1.9 & 0.0 \\
Managerial & 21.0 & 17.1 \\
Entrepreneurial & 17.2 & 13.7 \\
Worker & 4.5 & 13.7 \\
Other & 7.0 & 6.8 \\
N & 157.0 & 117.0 \\
\hline
\end{tabular}

Table 3: Mother's Occupation

\begin{tabular}{|lcc|}
\hline \multicolumn{1}{|l|}{ SQ 11 MOTHER'S OCCUPATION } & \\
\hline Upper Professional & 5.1 & Final Year \\
Low Professional & 10.8 & 3.4 \\
Upper Services & 27.4 & 13.4 \\
Low Services & 1.3 & 23.5 \\
Managerial & 5.7 & 2.5 \\
Entrepreneurial & 5.7 & 3.4 \\
Worker & 16.6 & 5.0 \\
Other & 27.4 & 20.2 \\
N & 157.0 & 28.6 \\
\hline
\end{tabular}

When the two different intake groups of law students ("first year" and "final year”) are compared (Table 2 and Chart 3), all higher occupational positions of the fathers of law students are more frequently reported in the later intake group (1990), with the 
exception of a slight reduction of reported upper public service positions of law students' fathers, and all lower positions (lower public service, worker) are here less frequently reported. Similarly, the reported levels of educational attainment of both parents are higher (higher occurrence of higher levels/ lower occurrence of lower levels) in the mow recent intake of law students (Tables 4 and 5, Charts 4 and 5). University degrees are no longer the almost exclusive achievement of only the fathers of law students: $40 \%$ of the students of the intake in 1990 report that their mothers hold a bachelor degree and 9\% report that their mothers hold a higher than bachelor degree (Chart 4). In this comparison of the different intake groups, it should be kept in mind, that the final year group of students is, as mentioned earlier, a much more varied sample as far as their admission is concerned, than the first year group where students come almost exclusively dimly from high school. However, the comparison also shows that the competition for entry has further homogenised the group of students who are eventually admitted at this stage, and that resourceful families are even more over-represented as compared with other student samples or the general population.

Table 4: Father's Educational Attainment

\begin{tabular}{|lcc|}
\hline \multicolumn{2}{|c|}{ SQ 12 FATHER'S EDUCATIONAL ATTAINMENT } & \\
\hline & First Year & Final Year \\
Primary & 2.5 & 5.0 \\
Some Secondary & 3.8 & 12.5 \\
School Certificate & 13.3 & 10.8 \\
HCS & 12.0 & 9.2 \\
Tertiary & 10.8 & 9.2 \\
Bachelor Degree & 30.4 & 32.5 \\
Higher Degree & 25.9 & 20.8 \\
Other & 1.3 & 0.0 \\
N & 158.0 & 120.0 \\
\hline
\end{tabular}


Table 5: Mother's Educational Attainment

\begin{tabular}{|lcc|}
\hline Q 13 MOTHER'S EDUCATIONAL ATTAINMENT & \\
\hline & First Year & Final Year \\
Primary & 3.8 & 5.0 \\
Some Secondary & 3.1 & 12.3 \\
School Certificate & 12.6 & 15.8 \\
HCS & 16.4 & 17.5 \\
Tertiary & 14.5 & 20.8 \\
Bachelor Degree & 40.3 & 20.8 \\
Higher Degree & 8.8 & 5.8 \\
Other & 0.6 & 0.8 \\
N & 159.0 & 120.0 \\
\hline
\end{tabular}

CHART 3: Father's Occupation

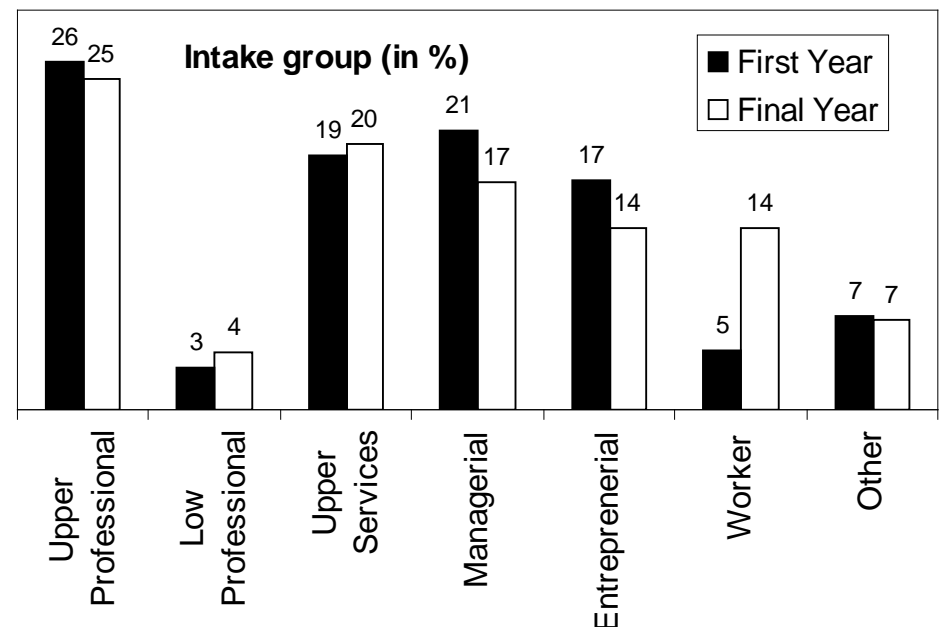


CHART4: Mother's Educational Attainment

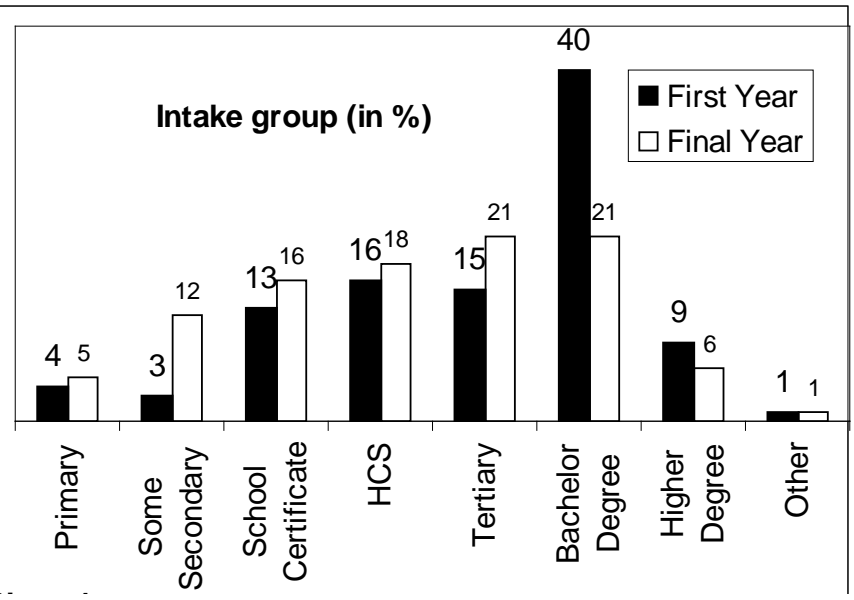

CHART 5: Father's Educational Attainment

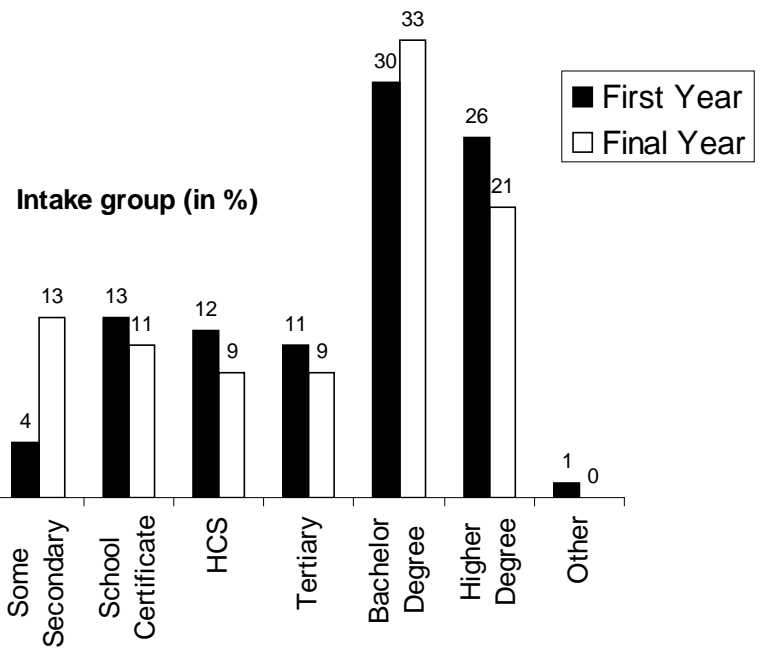


CHART 6: HSC Score by Mother's Educational Attainment

(in \%)

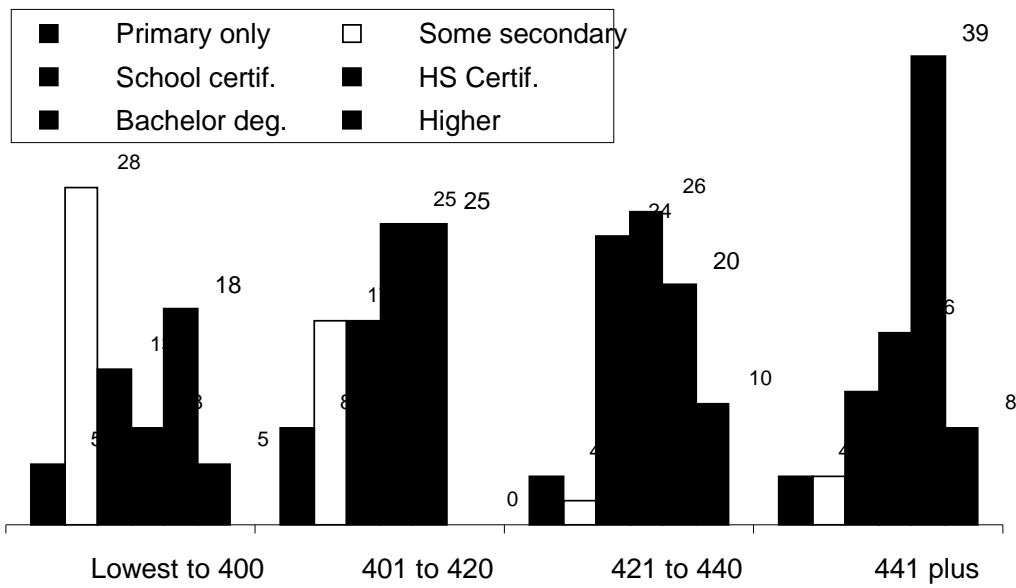

CHART 7: Mother's Educational Attainment by Father's Occupation

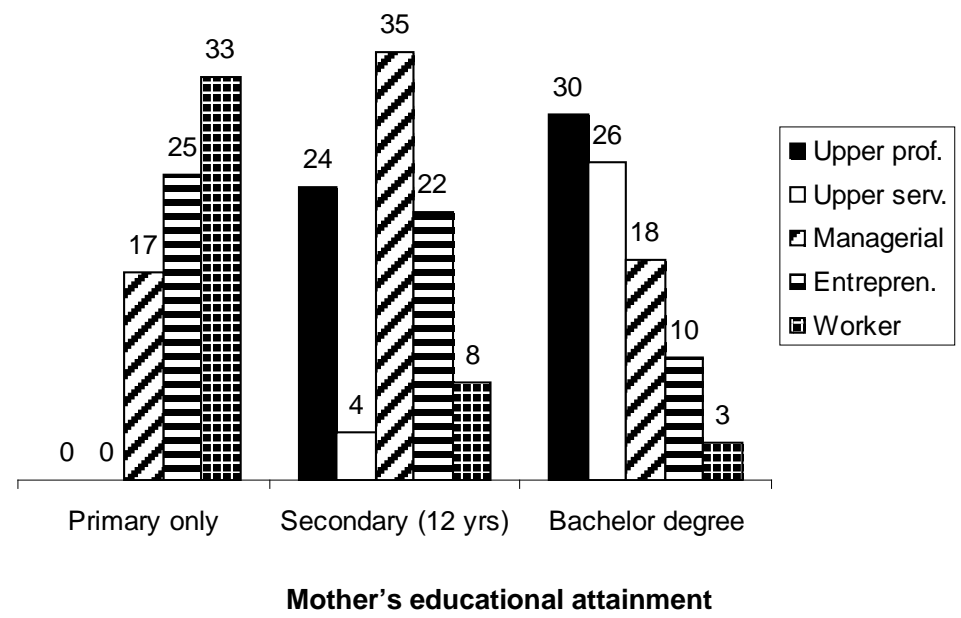




\section{CHART 8: Mother's Educational Attainment}

by Father's Education

Primary only $\square$ Secondary (12 yrs) $\bullet$ Bachelor degree $\Xi$ Higher

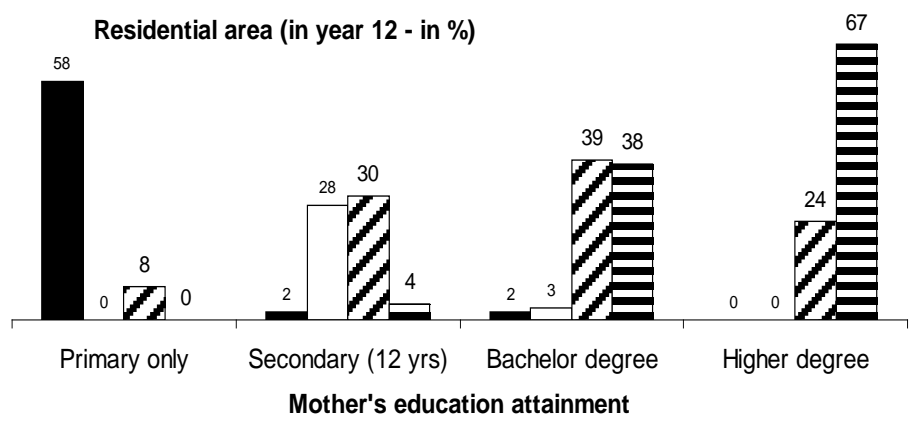

As noted earlier, there is a strong and significant tendency for couples overall to increase their individual resourcefulness by homogamic marital match-making. This observation applies clearly to parents of students who are eventually admitted to law school. Here, there is not only a higher than normally distributed chance that the parents of the students hold university degrees but also a higher chance that both parents hold such a degree compared with the population at large. Our data show that:

1 particularly, mothers of law students are highly resourceful as far as educational attainment is concerned, and far more so than women in the population at large; this high level of educational attainment of mothers is directly and positively related to the academic achievement of students at HSC level (Chart 6), and only statistically significant for mothers but not for fathers of law students;

2 that the fathers of law students have achieved, overall, a higher occupational status and a higher level of educational attainment than men in the Australian population at large and that they are predominantly married to partners who have attained similarly high or slightly higher levels of overall resourcefulness. Here high levels of educational attainment are the bargaining chip for women (mothers of law students) who are generally disadvantaged in their occupational careers when compared to men in general and to their male partners in particular (Charts 7 and 8). 
Socio-cultural background and access to the dominant culture. Variables which refer to a specific socio-cultural background of an individual, such as the country of birth of the parents and native language are generally referred to as "ethnic issues" and are as such not generally seen in the context of family and individual resources. Our theoretical framework discussed in section 2 suggests otherwise. It points to the intimate link between family resources, access to societal infrastructure and access to the dominant culture. The socio-cultural background, then, explains, to a high degree, the resourcefulness of families of law students as a result of a positive relation with Anglo-Saxon and/or Anglo- Celtic Australian language and culture (Tables 6, 7 and 8).

Our data show that an accumulation of cultural capital has been achieved here through effective intergenerational transmission of cultural capital in families where the parents, and possibly already the grandparents, were born in Australia and that the group of these students constitutes the overwhelming majority of law students. The next largest group of law students come from families who have not been born in Australia but in other sociocultural environments which are linked to the English culture (United Kingdom, New Zealand). ${ }^{39}$ Compared with this predominance of English socio-cultural patterns, other ethnic backgrounds are insignificant among law students, even if one takes into account the quite substantial number of students in the first year who report an Asian family background (compare Tables 6 and 7). A closer assessment of the language which is primarily spoken in these families reveals here also a dominance of English (Table 21). This finding suggests that many of these Asian students come from those countries which were former English colonies (Hong Kong, Singapore, Malaysia) and that their families must be assumed to command a high degree of resourcefulness (high occupational status of fathers, high level of educational attainment of mothers) precisely because they have access to English culture. ${ }^{40}$

Table 6: Mother's Country of Birth

SQ 14.2 MOTHER'S COUNTRY OF BIRTH

First Year

Australia

62.9
Final Year

69.2 


\begin{tabular}{|lcc|}
\hline Other Anglo & 15.1 & 10.8 \\
North Europe & 3.8 & 3.3 \\
South Europe & 3.8 & 8.3 \\
East Europe & 2.5 & 0.8 \\
Asia & 11.3 & 6.7 \\
Other & 0.6 & 0.8 \\
$\mathrm{~N}$ & 159.0 & 120.0 \\
\hline
\end{tabular}

Table 7: Father's Country of Birth

\begin{tabular}{|lcc|}
\hline SQ 14.3 FATHER'S COUNTRY OF BIRTH & \\
\hline & First Year & Final Year \\
Australia & 57.9 & 63.3 \\
Other Anglo & 16.4 & 17.5 \\
North Europe & 3.8 & 2.5 \\
South Europe & 5.0 & 7.5 \\
East Europe & 3.1 & 1.7 \\
Asia & 11.9 & 6.7 \\
Other & 1.9 & 0.8 \\
$\mathrm{~N}$ & 159.0 & 120.0 \\
\hline
\end{tabular}

Table 8: Primary Language Growing Up

\begin{tabular}{|lcc|}
\hline \multicolumn{1}{|c|}{ SQ 14.4 ENGLISH PRIMARY LANGUAGE GROWING UP } \\
\hline FES & First Year & Final Year \\
NO & $\mathbf{8 3 . 0}$ & $\mathbf{9 0 . 1}$ \\
Arabic & $\mathbf{1 3 . 0}$ & $\mathbf{9 . 9}$ \\
Cantonese & 0.6 & 0.8 \\
Other Chinese & 8.8 & 0.8 \\
\hline
\end{tabular}




\begin{tabular}{|lcc|}
\hline Croation & 0.6 & 2.5 \\
Estonian & 0.6 & 0.0 \\
French & 0.6 & 0.0 \\
German & 0.6 & 0.0 \\
Greek & 1.3 & 2.5 \\
Italian & 0.6 & 0.8 \\
Vietnamese & 0.6 & 0.0 \\
Serbian & 0.6 & 0.0 \\
$\mathrm{~N}$ & 159.0 & 120.0 \\
\hline
\end{tabular}

\section{FAMILY PROCESS}

A survey by questionnaire, using student's self-reports, is illsuited to capture reliably family processes and dynamics which go back a long way in their lives. Here the interviews with the students reveal more adequately how stable and supportive family environments contribute to take children and adolescents through their comparatively long educational careers and sustain students on robust levels of self-esteem and appreciation of self-worth. Students also report here the high degree of intensive consultation and discussion with their parents at incisive stages of their lifecareers, especially with the decision where to study and what to study at university :

... After talking to my parents, they just sort of said we leave it up to yourself and they sort of said you know maybe you should leave it open a little bit more, because you're still pretty young. As it was, I was only seventeen $(1-\mathrm{B} 2)$.

Well, my father was a lawyer, and I have a bit of an idea what lawyers did. He didn't really want to push me into the career, he even sort of recommended against it a couple of times when he came home after a hard day (4 - B2).

Because, when I finished my arts degree I felt law was a substantial career. Arts was interesting. I thoroughly enjoyed it but I thought, career-wise, law would be better. And I think parental desires as well played a role $(26-\mathrm{Bl})$.

Of course, there is not always agreement in family process: 
The reason why I wanted to study law was because when I came into the Bachelor of Education, I was accepted into the law degree. My parents thought it was a bad career for a woman and they persuaded me to become a school teacher. They thought that would be easier for me and I was persuaded at that age to do that $(28-\mathrm{B} 1)$.

It is consistent with such reports on the influence of family process on career decisions of students that law students, especially the younger ones, rank the importance of the information about their studies and career which they obtain through their parents, before they applied for admission to a law degree, fairly high and above the information which they obtained from career advice and information officials. As students grow older, this importance of parental consultation fades, retrospectively, ${ }^{41}$ behind the relevance of information obtained through their friends, and hew especially the friends who happen to be lawyers themselves (Tables 15 and 16).

Generally, it happened only rarely that students reported spontaneously on their family relations in the context of talking about their educational careers but neither did they mention any particular problems in their families in this respect. This could mean that the students take a favourable secure base for granted, especially since the group with which they mix at law school is so highly homogeneous and does not provide for many strikingly contrasting experiences. On the other hand, students are also aware of divisions among the student population which run exactly along the line of parental support:

And if you have to work [in order to support yourself] then it is just tough, but I just do not know how they expect you to be able to get through the course. And graduates are more likely not going to have the support of their parents. And so there is a marked sort of division between the undergraduates who most likely are going to have the support of their home $(2-B 8)$.

One thing I find difficult is, this being a full-time course, I think it caters very much for people who are being supported by their parents. The demographics on that are obvious. I think it is incredibly difficult to support yourself and do reasonably well (15 - B11).

There is not enough variety of people here ... And that reflects on the work that they [students at law school] do and what they expect from us and what they expect from the teachers and what they expect from the courses ... In that I mean they tend to come from a very sort of wealthy background, their parents are very well educated ... It is a very 
elitist selection (16 - B7).

\section{Socialisation and Education in Secondary Schools}

The Type of Secondary Schools

The lively public debate on secondary schools in NSW highlights the importance which the general public here attributes to formal education. This debate draws a more or less sharp distinction between state (public) schools and non-state schools and attributes the different outcomes of their selective operations to a perceived difference in the quality of the education which the different school types provide. Given the ambiguous operations of education organisations as discussed in this study, any account on what high schools actually achieve differently from each other must be viewed with suspicion. We can only safely assume that any significant difference in educational practices of the different types of secondary schools rests solely on the (different) outcomes of different selective admission practices. In other words, the quality of the performance of secondary schools is the quality of the selected student populations, or, the more selective the admission practices of particular types of high schools are, the easier it is for these schools to allege superior institutional performance.

The data reported by the law students support such assumptions. When we correlate the HSC score of law students with the type of high school they graduated from, we find no statistically significant relation between the different HSC scores and any particular type of high school. On this count, then, no particular type of high school delivers a particular type of "better student" as far as admission to law school is concerned.

Table 9: Type of School of Graduation

\begin{tabular}{|lcc|}
\hline SQ16 SCHOOL TYPE & & \\
\hline & First Year & Final Year \\
Selective & 11.9 & 10.8 \\
Non-selective & 18.2 & 25.8 \\
Catholic & 22.6 & 26.7 \\
Independent & 45.3 & 35.0 \\
\hline
\end{tabular}




\begin{tabular}{|lcc|}
\hline TAFE & 0.6 & 0.0 \\
Other & 1.3 & 2.7 \\
$\mathbf{N}$ & $\mathbf{1 5 9 . 0}$ & $\mathbf{1 2 0 . 0}$ \\
\hline
\end{tabular}

In contrast, significant positive correlations are found when we relate the type of school to the level of family resources available in the families of law students. Here it is evident that it is the observed strength of family resources and family process of the families of students who are eventually admitted to law school which enables these families to have their children admitted to selective rather than to non-selective secondary schools in disproportionately high numbers (Table 9). The selective accumulation of these student populations, in turn, achieves the higher performance levels of selective schools. This applies to selective schools both in the state and in the private sector of secondary education. ${ }^{42}$ When we compare the different intake samples of law students, we find that in the group of students who have been admitted in 1990 (first year law) and directly from secondary school, the proportion of graduates from private schools, that is, Catholic and independent schools, is considerably higher than in the group of students who have been admitted 1986 or earlier, and who are more varied in their ways of finding entry to law school. Given the different composition of our samples, these findings are partly an indication for the tendency that, in the light of higher competition from increasing numbers of academically highly qualified children for the admission to restricted courses of study like medicine and law, there is a stronger move to selective schools generally, and partly that admission practices of the law school at present favour the direct admission from high school. Students from selective schools dominate this group which is favoured by present admission practices. In other words, also the admission practice of the law school prefers, as do selective schools, what the educational system already prefers ${ }^{43}$ This tendency accentuates the fairly established pattern, pointed out in the framework of our underlying model above that the relative small sector of selective schools provides, relatively and in absolute numbers, more entrants to law school than the large sector of non-selective public schools. Stuck with greater numbers of students with a greater variety of personal 
characteristics, non-selective high schools classify comparatively less students with academic credentials which qualify for university studies, and they classify even less students with academic credentials which qualify for admission to law school.

We must assume, then, that rather than different approaches to education, different family styles determine the operational outcomes of the educational practices of selective and non-selective secondary schools respectively. These are, in turn, reflected in their classification schemes. Parents who are particularly committed to the formal education of their children perceive admission to a selective school to express such a parental commitment and they choose selective schools for their children for this reason. This, in effect, self-selection of families who are committed to formal education, provides selective schools with a highly homogeneous population of largely motivated students while at the same time preventing a more favourable mix of students in the non-selective public schools.

Also at this level, we can observe specific operations of the structural coupling of economics and education. Parents who are committed to education and who are in a position to pay but have not attained high levels of educational attainment themselves can participate, to a degree, in the selective operation of secondary schooling by "buying" their children a "better education" in selective (private) schools. Our data show that it is predominantly families where fathers are reported to hold managerial and entrepreneurial occupational positions who send their children to private (independent) schools, while students from families with fathers who are reported to hold upper professional or upper public service occupational positions are less frequently reported to have their children exclusively admitted to private schools (Charts 10 and 11).

Parents who are committed to the value of formal education are also committed to the long-term goal of university studies for their children. Students who come from such families internalise such expectations and are pulled along toward this goal. They find it hard not to accept such middle- class and upper- middle-class values towards university studies. In contrast, students in nonselective schools are, on the whole, subjected to a more diffuse set of pulls. Among them, and depending on local mixes of student 
populations, the variance of local sub-cultures and the macroeconomic climate, to exit the education system altogether, to leave the parental home and to earn money or to set up own families must be seen as very strong motivations which may override the value of formal education (discussed in section 4.4).

Chart 9: Type of School of Graduation of Student

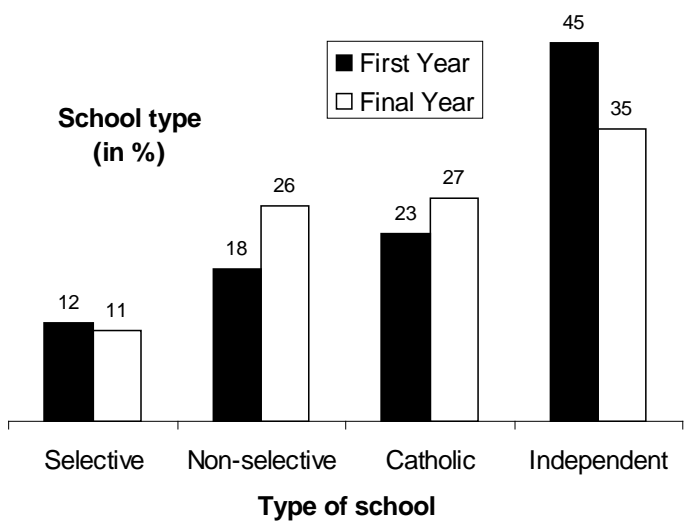

Chart 10: Father's Occupation by School Type (first year)

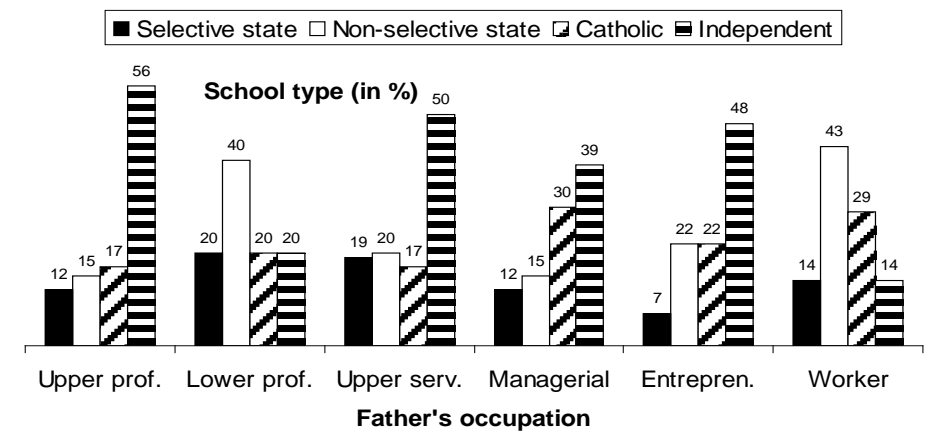


Selective state $\mathbf{\square}$ Non-selective state $\mathbf{\square}$ Catholic $\boldsymbol{\nabla}$ Independent ${ }_{52}$ School type (in \%)

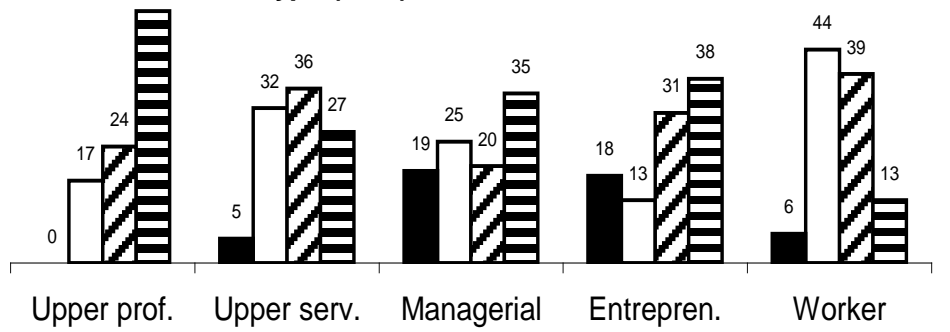

Father's occupation

When we correlate the type of high school from which law students have graduated with the form of entry to law school, it is evident that, while a majority of these students have come directly from Catholic and independent private schools into the combined degree courses (77\% and $84 \%$ respectively), greater numbers of students from non-selective schools come to the law school via the detour of another degree, that is, as graduate students (61\% vs. 19\%). ${ }^{44}$ This observation can serve as an indicator of the different strength of the pull of the value of formal education as experienced by the students in the different types of high school: it is strongest in independent schools and weakest in non-selective schools, with the selective state schools and Catholic schools taking up intermediary positions.

Our data show, then, that the direct route from a selective secondary school to law school is the best predictor for eventual admission to law school. Not surprisingly, the students from selective schools dominate the upper levels of educational attainment because their families dominate the market of favourable family resources and family process. The pool from which law students are drawn is formed almost exclusively here and not on any later stage in the selection process. 


\section{SOCIO-ECONOMIC SEGREGATION AND SECONDARY}

\section{SCHOOLS}

Although non-selective schools have no direct control on the student population drawn from respective public school precincts, also here there is a selective effect due to the socioeconomic characteristics of those urban areas in which high schools are situated. The Sydney metropolitan area, in which $78 \%$ of the law students in our sample lived when they went to high school, is characterised by a significant socioeconomic segregation of the residential areas. We must assume that, in addition to the significant prevalence of selective schools in the educational careers of law students, also the students who come from nonselective schools have been selected through schools which are predominantly situated in the more affluent residential areas of Sydney. We can expect that this minimises the differences between their personal profiles and those of the students who come from selective schools.

In order to test this proposition, we grouped the residential areas of Sydney according to a low, medium or high socio-economic level $^{45}$ and we assessed the distribution of the reported law students' place of residence in year 12 accordingly. ${ }^{46}$ It was found that $45 \%$ of all law students in the sample lived in a suburb with a high socio-economic level, while $24 \%$ and $7 \%$ lived in a suburb with medium and low socio-economic levels respectively. The link of such a privileged living with selective high school attendance is clearly positively related (Chart 12). The great majority of those students who went to a selective high school lived in a suburb with high or medium socio-economic level in their last year at school (year 12). However, also those students who have come to the law school via non-selective schools have predominantly lived in the more affluent suburbs of Sydney, even if a substantial number here, in contrast to students who go to selective high schools, have lived in a suburb with a lower socio-economic level, and probably also went to school there. All in all, it is evident that not only selective schools but also selective socio-economic segregation of private living and public schooling add to the homogeneous profile of the law student population.

The socio-economic segregation between residential areas and 
their more or less supportive infrastructure is positively related to the level of family resources. Surprisingly, however, the occupational status of the father appears not to be the crucial factor for such a link. Our data show that it is above all the educational attainment of the mother which provides the statistically significant relation (Chart 13). The higher the educational attainment of the mother the more frequently the student resided in an affluent suburb of Sydney while attending high school. This finding points, again, to the pivotal role of women who do not only organise predominantly the internal working of families but also liaise the family system with the social environment in general and with the resource infrastructure and the availability of services in that environment in particular. We, therefore, can expect a greater influence of mothers on the choice of living arrangements than that of fathers. In view of such reasoned residential choices by mothers, living arrangements must be seen as a further measure of resource maximisation by families who are already resourceful. 
Chart 12: Type of School by Type of Residential Area

(year 12)

- Type 1 (low income) $\square$ Type 2 (medium income) Type 3 (high income)

Residential area (in year 12 - in \%)

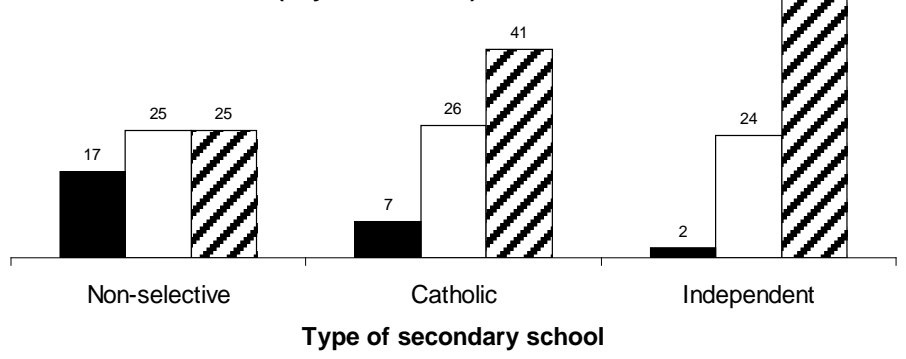

The evidence for a mediating role of the family living arrangements is further supported by the finding that also the use of the primary language in the family home is distributed along the lines of socio-economic segregation of residential arrangements, with the highest use of English as that primary language by the families who live in the most affluent suburbs (91\%), and the lowest use by families who live in the least affluent suburbs (70\%). However, this difference is small and statistically not significant since the number of law students who did not speak English as a primary language at home is very small overall (Table 8).

\section{SECONDARY SCHOOL CURRICULA AND THE ADMISSION TO LAW SCHOOL}

Students who come to law school have studied a wide variety of subjects at high school and there is no prerequisite requirement on part of the law school for any particular subject (Tables 10 and 11).

However, in line with the findings above which relate to the importance of access to dominant language and culture, we find that certain subjects are more intimately related to high academic achievement and so, to admission to law school, than others. Only in this limited sense these subjects, namely English and Modern History appear to have a certain predictor value with regard to eventual admission to law school.

However, a case could be made that English and Modern History are most clearly related to the development of social and 
intellectual competence in adolescents and young adults in Australia, because issues dealt with by these subjects allow for a considerable degree of cultural communication with children and adolescents in their socialisation processes and in the educational environment of home and school.

Our data support such an argument. The study of English in year 12 by students who are eventually admitted to law school is positively ${ }^{47}$ related both to the levels of educational attainment of their mothers and to the occupational position of their fathers. This means, that the higher the levels of mothers' educational attainment and fathers' occupational status are, the greater is the frequency with which their children have studied English in year 12. Law students who had taken English in year 12 reported only $10 \%$ and $12 \%$ of mothers with only primary school or some secondary school levels respectively but $83 \%$ of those who had finished a bachelor degree. Similarly, law students who had taken English in year 12 , reported $66 \%, 45 \%$ and $41 \%$ of the fathers with an upper professional, managerial or upper civil service occupational status but only $18 \%$ with the status of a worker or similar.

Chart 13: Mother's Educational Attainment by Type of Residential Area (in year 12)

— Type 1 (low income) $\square$ Type 2 (medium income) $\mathbf{0}$ Type 3 (high income)

Residential area (in year 12 - in \%)

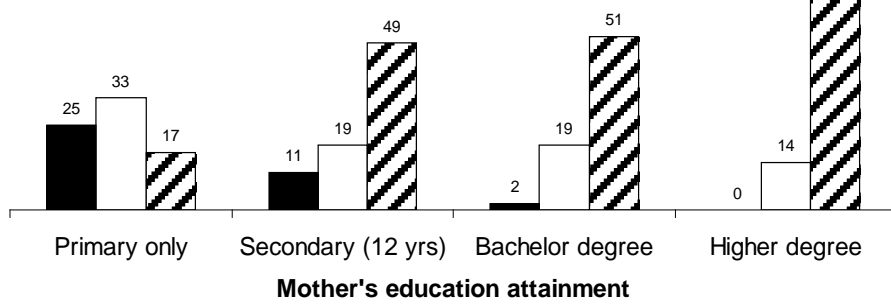


Table 10: Year 12 Subjects

\begin{tabular}{|c|c|c|}
\hline & First Year & Final Year \\
\hline Accountancy & 0.0 & 28.6 \\
\hline Agriculture & 25 & 1.7 \\
\hline Art & 5.7 & 3.4 \\
\hline Biology & 8.3 & 11.8 \\
\hline Chemistry & 459 & 36.1 \\
\hline Croatian & 0.6 & 0.8 \\
\hline Economics & 40.8 & 37.0 \\
\hline Engineering SC & 1.3 & 0.0 \\
\hline English & 100.0 & 70.6 \\
\hline Estonian & 0.6 & 0.0 \\
\hline French & 19.7 & 74.3 \\
\hline General Studies & 19.7 & 31.9 \\
\hline Geography & 6.4 & 3.4 \\
\hline Geology & 1.3 & 0.8 \\
\hline German & 7.6 & 92 \\
\hline Greek Clas & 1.3 & 0.0 \\
\hline Greek Mod & 1.3 & 0.8 \\
\hline History Ancient & 17.2 & 185 \\
\hline History Modern & 34.4 & 319 \\
\hline Home Science & 1.3 & 0.8 \\
\hline Italian & 1.9 & 0.8 \\
\hline Japanese & 2.5 & 0.0 \\
\hline Latin & 17.2 & 4.2 \\
\hline Legal Studies & 0.6 & 0.0 \\
\hline Maths & 93.0 & 66.4 \\
\hline
\end{tabular}




\begin{tabular}{|lcc|}
\hline Music & 5.1 & 3.4 \\
Physics & 35.7 & 27.7 \\
Religious Studies & 1.3 & 0.8 \\
Russian & 0.6 & 0.0 \\
Science & 10.2 & 1.7 \\
Social Psychology & 0.6 & 0.0 \\
Society \& Culture & 1.3 & 0.0 \\
Speech \& Drama & 1.3 & 0.0 \\
Visual Arts & 1.3 & 0.0 \\
$\mathrm{~N}$ & 157.0 & 119.0 \\
\hline
\end{tabular}

Table 11: Year 12 Subject - 4 Units Maths

\begin{tabular}{|lcc|}
\hline SQ 8.2 & 4 UNIT MATHS IN HSC & \\
\hline & First Year & Final Year \\
YES & 47.4 & 15.3 \\
NO & 51.3 & 56.8 \\
N & 156.0 & 118.0 \\
\hline
\end{tabular}

As far as Modern History in year 12 is concerned, which is generally much less popular among law students than English, Maths, Economics or some of the natural science options (Table 10 ), the proposition is only statistically sup ported for the variable of the educational attainment of mothers, however, here on a high level of significance. ${ }^{48}$ While law students who have done Modern History in year 12 only report 4\% and 7\% of mothers with primary or some secondary schooling levels, they report $34 \%$ of mothers with a completed bachelor or similarly high university degree. ${ }^{49}$

These contrasts are less pronounced but persist in the natural science subjects like chemistry, physics, maths or the highly specialised subject Mathematics - 4 units. Therefore, it is important to note that the subjects chosen for year 12 in themselves do not "produce" more or less social and intellectual competence in 
the students but allow for a different degree of expression of competence which the students already have. Here the choice of English and Modern History in year 12 appear to be better predictors for the eventual admission to law school than maths, chemistry or physics.

A more important role may also be played by the educational practices in the high schools to suggest and provide preferences for particular subjects. Our data show that there is indeed a systematic bias towards the major subjects (English, Maths, 4 unit Maths, Physics, Modern History) being most consistently taken by the students from independent schools. However, this positive link of choice of subject to selective school is only statistically significant for Modern History. The correlation with the subject Maths and 4 unit Maths reaching only moderate levels of significance $(p=0.0527$ and $\mathrm{p}=0.0385$ ). This means that the choice of subjects, at best, covaries with the particular practices of the high school and is not a predictor for admission to law school by itself. These classification practices of respective high schools constitute the "academic credentials" of any given student, and are the most important factor in determining his or her entry to tertiary education, or - as in our case - admission to a combined law degree (Table 12).

Table 12: Entry Score

\begin{tabular}{|lcc|}
\hline SQ 8.2 & 4 UNIT MATHS IN HSC & \\
\hline & First Year & Final Year \\
YES & 47.4 & 15.3 \\
NO & 51.3 & 56.8 \\
$\mathbf{N}$ & $\mathbf{1 5 9 . 0}$ & $\mathbf{1 2 1 . 0}$ \\
\hline
\end{tabular}

\section{THE CHOICE OF STUDYING LAW}

The last years at high school set the scene for important career decisions to be made by the students. Their reports after admission to law school reflect, retrospectively, that such decisions were not reached overnight. More surprisingly, it emerges from these reports that, for most of the students, the entry to law school was not a 
clear-cut choice or the preferred option but the more contingent result of vexing processes of narrowing down the field of options by exclusion of other options or by sheer serendipity. Typically, students report frequently a competing preference for both law and medicine ${ }^{50}$ - once it was clear that a sufficiently high level of the HSC score was achieved. This dilemma was ultimately resolved by reference to some further circumstantial factors:

To some extent it was partial because I had done very well at school. But the idea of becoming a doctor has never really interested me ... I turn green at the sight of blood and all sort of terrible things... and I've been very interested in debating at school. I've done quite well and the law seemed to fit in very nicely with that $(3-\mathrm{Bl})$.

[Law was] the course with a high aggregate that I could get into because it was next to medicine at that time. And that's mainly the reason because it was the thing to be $\ldots(4-\mathrm{Bl})$.

However, for many students the choice was even more indeterminate:

It's just something I arrived at. I often think how glad I am now that I have got from where I am and [that] I h've chosen what I h've done. But the more I think about it it's just really a matter of luck. There was never any time when I sort of thought "Ah! That's what I want to do", because I saw Dad or anything like that $(4-\mathrm{B} 2)$.

Two aspects of law appear to make it difficult for high school students to arrive at the decision to study law as the preferred choice in a more determined manner. The first is the relative social distance and cultural artificiality of the operation of law in the perspective of high school students. Students cannot ground their references to law on any of the traditional academic subjects in high school. While they collect references to law in a number of different subjects, none of them covers the question what law "is" in its entirety. The newly introduced subject "Legal Studies” may address some of these problems of identification but it may also add to the confusion of high school students, given the complexity of the operation of legal systems.

The second is the work practice definition of law rather than the academically (scientifically) developed definition of the discipline.

This traditional definition of law as "what lawyers do" may make the career choice easier but it still leaves in doubt whether this is what academically highly achieving students want to study at university, especially since students are aware that law is obviously 
more than what lawyers do. Here the combined degree has greatly enhanced the attractiveness of studying law at university because it allows for a sharper focus on the particular academic interests of high school students as forged in the institutional setting of high schools while at the same time retaining the prospect of an established vocational career.

The answers of the students to the question why they wanted to study law appear to reflect this unique historical and cultural feature of law as an academic discipline when they, on the one hand, rank interest as a reason highly and, on the other hand, rank the technicality of having had a sufficiently high entry score almost as highly (Table 13). ${ }^{51}$ Here, the responses to the questionnaire typically gloss over the more complex stories of the decisionmaking in the past. These stories are reflected more adequately by the students' own narratives. It emerges from such more detailed accounts, for instance, that the value interest is ranked so highly because this category has a different connotation for each student with regard to their choice; the high ranking is an aggregate of a number of diffuse notions rather than a measurement of concrete expectations of students. Furthermore, the references to this value include the reference to the combined law degree rather than to law itself. In this way, the interest for studying law may be subsumed under the interest for subjects studied for the other degree in the combined degree framework. This suspicion that not law but something else provided the intrinsic interest for studying law is supported by our finding that the curricula of the law school by themselves had practically no appeal whatsoever for the students when they decided to study law. ${ }^{52}$ The relationship between the reasons for studying at Sydney University with the students' ranking of reasons indicates that the (academic) prestige of the University of Sydney prevails as the dominant reason. Compared with this reason, the teaching programme of the law school or the prestige of the law school are less important considerations (Table 21). We must conclude that, if there is any enthusiasm for law as an academic discipline in the students' reports, it is rather muted. 
Table 13: Results of Completed Law Subjects

\begin{tabular}{|lcccc|}
\hline $\begin{array}{l}\text { SQ9 RESULTS OF COMPLETED COMPULSORY LAW SUBJECTS } \\
\text { (Final year) }\end{array}$ & Fail & Pass & Dist. & H. Dist. \\
\hline Legal & 0.0 & 33.3 & 13.3 & 1.7 \\
Instruction & & & & \\
Contracts & 0.0 & 44.2 & 14.2 & 1.7 \\
Torts & 0.0 & 43.3 & 21.7 & 0.8 \\
Criminal & 0.8 & 23.5 & 20.2 & 2.5 \\
Constitutional & 4.2 & 44.2 & 11.7 & 0.8 \\
Administrative & 0.8 & 36.7 & 15.0 & 2.5 \\
Real Property & 0.8 & 37.5 & 18.3 & 0.8 \\
Success \& Pers & 0.0 & 37.5 & 17.5 & 5.8 \\
Prop & & & & \\
Equity & 0.0 & 34.2 & 11.7 & 2.5 \\
Company Law & 0.0 & 16.7 & 18.3 & 0.8 \\
International & 0.0 & 20.0 & 31.7 & 2.5 \\
Evidence & 0.0 & 14.3 & 24.4 & 3.4 \\
Jurisprudence & 0.0 & 2.5 & 0.8 & 1.7 \\
N FINAL = 120 & & & & \\
& & & & \\
\hline
\end{tabular}

In summary, then, we find that law becomes an option for students not by its intrinsic attractiveness but, above all, when the achieved high school marks put a legal career into reach. However, this importance which high school leavers accord to their HSC score - rather than to their potential career paths — fades with the years spent in law school. First year students and last year students view the reasons for studying law, retrospectively, quite differently.

While it is noteworthy that law students overall rank the value of serving others and the community ("helping") below the value of "interest" but above the value of high income to be earned by lawyers and above the favourable employment perspectives, it is important to point out that this result is influenced by gender-bias 
in a curious way. When correlating the ranking of Helping with gender, we find that female students - who represent a majority of law students in our samples (54\%) — value this reason significantly $(p=0.016)$ higher than male students. On closer examination, however, this appears to be so because women are more reluctant to reject this value as a reason for studying law altogether: the small proportion (only 15\%) ${ }^{53}$ of female students and male students who rank this reason as very important is exactly the same and it is never explicitly mentioned as a reference in the narratives established by the interviews of either male or female students as the main reason why they choose law.

As far as ranking of reasons is concerned, the prospects of legal practice as a career with high income and good employment opportunities are highly attractive features to advocate this choice. Also in this instance, perception more than recall appears to direct the students' reports of their reasons for studying law; thus, perception changes as students make their way through law school. While younger students in first year law, perhaps unrealistically, rank the value of high income higher than the value Employment Opportunities, the older law students who approach the end of their studies have apparently a more sober picture of their future careers; they are more concerned with employment opportunities rather than with high income. Also this result is influenced by genderbias: while only $9 \%$ of the males rate high income as not at all important but 32\% as a somewhat important factor in their choice, $24 \%$ of the women report that it was not at all a factor and $15 \%$ that it was a somewhat important factor. ${ }^{54}$ In contrast, the value Employment Opportunities is ranked by both female and male students almost identically high as important (somewhat important, women: 28\%, men: 27\%; very important, women: $10 \%$, men: $10 \%$ ). These results are independent of the type of high school environment from which the students come, which is further indication that the law student population, once selected through admission to law school, shares largely the same values independently of the different family and, consequently, school backgrounds. Here only the students who come from Catholic schools appear to differ somewhat by ranking the value of a high income as a reason to study law higher than their peers from other schools. This observation adds to a list of indicators which show 
the particular (up ward) social mobility of this law student population. ${ }^{55}$ It appears that it is the upward social mobility of this group rather than the religious values which is expressed in their instrumental attitude toward studying law and which sets this group of students apart from the rest of the law student population.

The spread of ranking of the reasons for studying law is a reflection of the diffuse picture of law which students have before their decision to study it and which depends, therefore, highly on more personal, almost arbitrary, circumstances. Notably the reason that there was nothing else which seemed to appeal at the time rates very highly with both first year law students and older students. It is this default reason which transpires most clearly as the main reason for the choice of law in the narratives:

Well, I thought I'll do a combined degree because the fact that I wasn't really sure what I was going to do when I left school. I thought it was the most open sort of degree in that you could branch off once you have finished." "Actually, the day before the UCAC forms had to be in, I was going for medicine. I only changed about an hour before I was going to put it in because I thought if I did medicine I'll be sort of following the mob and you have to be a doctor. Whilst if you do economics/law, you can sort of think about whether you want to move into economics or law $(1-1)$.

It's just mainly I think law is a fairly flexible degree and so it could be quite useful. I did my arts degree for instance. There's such a huge emphasis you know, these days on qualifications and education. Arts degrees aren't looked on very kindly ... (2-1).

If you are not an Honours student or something and if you do not do well then you're often better off not having done it. But I still can study and I had a sort of vague interest in law, so I just decided to continue on $(2-2)$.

With this view on the way in which academically highly achieving students end up choosing to study law, it may be concluded that if law students are frequently seen to be colourless among their peers from other faculties this has a lot to do with the colourlessness of law as an academic discipline. ${ }^{56}$

When students were asked how they rated the quality of their information about the requirements to enter law prior to admission to law school, they ranked the information which they obtained as fairly high. The quality of the information about the actual length of studies and about the career prospects of lawyers were ranked slightly lower (Table 14). Here older law students, who are about to 
enter legal careers, find more frequently than first year students that, retrospectively, their knowledge about being a lawyer was rather limited when they decided to study law.

Table 14: Information About Studying Law

\begin{tabular}{|lcccll|}
\hline SQ 8.2 & 4 UNIT MATHS IN HSC & & \\
\hline & $\begin{array}{c}\text { First } \\
\text { Year }\end{array}$ & $\begin{array}{c}\text { Final } \\
\text { Year }\end{array}$ & $\begin{array}{c}\text { Ranking First } \\
\text { Year }\end{array}$ & $\begin{array}{c}\text { Ranking Final } \\
\text { Year }\end{array}$ \\
Requirements & 4.2 & 4.1 & 1 & Requirements & Requirements \\
Length & 3.4 & 3.4 & 2 & Length & Length \\
Being a & 2.7 & 2.2 & 3 & Being a Lawyer & Being a Lawyer \\
Lawyer & & & & & \\
$\mathbf{N}$ & $\mathbf{1 5 9 . 0}$ & $\mathbf{1 2 1 . 0}$ & & & \\
\hline
\end{tabular}

Primary group relations are, as mentioned earlier, fundamental for the cognitive processes in individuals, and our data show that predominantly relations of this kind have provided law students with the main inputs in their decision-making on career options. Students accord the highest relevance to their friends, possibly lawyer friends and parents (Table 15). As we have seen earlier, the perception of such a retrospective relevance of the information which law students obtained changes with their different life-cycle stages at the time of being questioned. As they grow older, friends and colleague-friends are seen to be more important and parents less important for providing relevant information.

Interestingly, also the media occupy a high ranking with reference to how information was obtained. However, this should not be seen not as a direct impact of this information source on the students but rather as the operation of primary relations with parents and friends which direct, support and mediate the interest in and the consumption of media releases on possible legal careers and the operation of law itself. Here, obviously, the exploitative dramatisation of legal action, especially in the areas of criminal law and courtroom-drama, exercises considerable appeal also for law students. 
Table 15: Quality of Sources of Information Regarding

Legal Studies

\begin{tabular}{|c|c|c|c|c|c|}
\hline \multirow[b]{2}{*}{$\begin{array}{l}\text { Careers } \\
\text { Adviser }\end{array}$} & \multirow{2}{*}{$\begin{array}{l}\text { First } \\
\text { Year } \\
1.9\end{array}$} & \multirow{2}{*}{$\begin{array}{l}\text { Final } \\
\text { Year } \\
1.6\end{array}$} & \multicolumn{2}{|c|}{ Ranking First Year } & \multirow{2}{*}{$\begin{array}{l}\text { Ranking Final } \\
\text { Year } \\
\text { Lawyers - } \\
\text { Friends }\end{array}$} \\
\hline & & & 1 & Friends & \\
\hline $\begin{array}{l}\text { Work } \\
\text { Experience }\end{array}$ & 1.9 & 1.6 & 2 & $\begin{array}{l}\text { Lawyers - } \\
\text { Friends }\end{array}$ & Friends \\
\hline Friends & 3.5 & 2.0 & 3 & Parents & Media \\
\hline Siblings & 1.7 & 1.4 & 4 & Media & Parents \\
\hline Parents & 2.2 & 1.8 & 5 & $\begin{array}{l}\text { Lawyers — } \\
\text { Other }\end{array}$ & $\begin{array}{l}\text { Lawyers — } \\
\text { Other }\end{array}$ \\
\hline $\begin{array}{l}\text { Lawyers - } \\
\text { Friends }\end{array}$ & 2.4 & 2.2 & 6 & $\begin{array}{l}\text { Work } \\
\text { Experience }\end{array}$ & $\begin{array}{l}\text { Work } \\
\text { Experience }\end{array}$ \\
\hline $\begin{array}{l}\text { Lawyers - } \\
\text { Other }\end{array}$ & 2.0 & 1.7 & 7 & $\begin{array}{l}\text { Careers } \\
\text { Adviser }\end{array}$ & Careers Adviser \\
\hline Law School & 1.4 & 1.4 & 8 & Siblings & Careers Centre \\
\hline $\begin{array}{l}\text { Careers } \\
\text { Centre }\end{array}$ & 1.5 & 1.5 & 9 & Careers Centre & Law School \\
\hline Media & 2.2 & 1.9 & 10 & Law School & Siblings \\
\hline Other & 0.3 & 0.6 & 11 & Other & Other \\
\hline $\mathbf{N}$ & 159.0 & 121.0 & & & \\
\hline
\end{tabular}

The information obtained through contacts with lawyers generally and through work experience takes up middle positions in the ranking of students. This is due to the less frequent occurrence of such events in the lives of law students as compared with the frequent and intensive (highly valued) contacts with friends and parents. Contacts with formalised providers of information like career centres or career advisers are nominated even less frequently. This casts some doubt on the effectiveness of such services. Most surprisingly, however, the law school itself receives the lowest ranking by law students as far as providing information is concerned. This may indicate, once more, the distance of legal 
education from the life-world of high school students or even law students. On the other hand, the law school may be perceived as not being in a position to provide any useful or necessary information prior to admission. Finally, this may indicate a retributive attribution of "bad marks" to the law school on part of the law students for not being sufficiently present at the market places of information for high school students or for providing only a poor service when students need such information most.

Overall, law students are not different from general populations in obtaining relevant information predominantly through informal communication channels rather than from formal providers of information and valuing that informally received information higher than the formally provided information. However, this fundamental importance of the immediate social environment, that is, face-to-face relations, highlights here the particular social environment from which these students come. This environment produces - by the mere frequency of social contacts with relatives or friends who are lawyers or who know lawyers - more references to law and legal careers for eventual law students than exist for a general population in NSW at large. Quite in contrast, the general population has hardly any of such positive references to law in operation and they avoid contact with the law, where possible, altogether. ${ }^{57}$ The assumption that the high occurrence of positive or friendly contacts with lawyers is a reinforcing factor for the selective effect of the social background in career decisions is supported when we correlate this variable with the occupational status of the fathers of law students. Here $47 \%$ of the children of fathers with upper professional occupational status but only $9 \%$ of the students with fathers with lower professional status, $5 \%$ of the students with fathers with entrepreneurial occupations and $2 \%$ of the students whose fathers are reported with the status of a worker, rank this source of information as important and relevant for their decision to study law..$^{58}$

What has been said above about valued information concerning the study of law applies also to the value which law students attach retrospectively to the informations which they obtained concerning a possible legal career prior to admission to law school (Table 16). However, here information is more sharply focused on factual advice about what lawyers do and on people who are lawyers. In 
this sense, informal contacts with relatives or friends who are lawyers aw valued highest, while also information about legal practice obtained through the media, with the qualifications mentioned above, plays an important role for the decision to study law. Further, the contacts with lawyers in general am valued more highly than the information obtained through the discussions with parents or friends. Also here formal advice obtained from official career advisers plays a minor role, including information directly obtained from the law school.

Table 16: Quality of Sources of Information Regarding Legal Career

\begin{tabular}{|c|c|c|c|c|c|}
\hline & $\begin{array}{l}\text { First } \\
\text { Year }\end{array}$ & $\begin{array}{l}\text { Final } \\
\text { Year }\end{array}$ & \multicolumn{2}{|c|}{ Ranking First Year } & $\begin{array}{c}\text { Ranking Final } \\
\text { Year }\end{array}$ \\
\hline $\begin{array}{l}\text { Careers } \\
\text { Adviser }\end{array}$ & 1.8 & 1.5 & 1 & $\begin{array}{l}\text { Lawyers - } \\
\text { Friends }\end{array}$ & $\begin{array}{l}\text { Lawyers - } \\
\text { Friends }\end{array}$ \\
\hline $\begin{array}{l}\text { Work } \\
\text { Experience }\end{array}$ & 1.9 & 1.7 & 2 & Media & Media \\
\hline Friends & 1.7 & 1.8 & 3 & Lawyers - Other & $\begin{array}{l}\text { Lawyers - } \\
\text { Other }\end{array}$ \\
\hline Siblings & 1.4 & 1.4 & 4 & Parents & Parents \\
\hline Parents & 1.9 & 1.9 & 5 & Work Experience & Friends \\
\hline $\begin{array}{l}\text { Lawyers - } \\
\text { Friends }\end{array}$ & 2.5 & 2.2 & 6 & Careers Adviser & $\begin{array}{l}\text { Work } \\
\text { Experience }\end{array}$ \\
\hline $\begin{array}{l}\text { Lawyers - } \\
\text { Other }\end{array}$ & 2.0 & 1.9 & 7 & Friends & Law School \\
\hline Law School & 1.2 & 1.7 & 8 & Siblings & $\begin{array}{l}\text { Careers } \\
\text { Adviser }\end{array}$ \\
\hline $\begin{array}{l}\text { Careers } \\
\text { Centre }\end{array}$ & 1.3 & 1.4 & 9 & Careers Centre & Siblings \\
\hline Media & 2.0 & 2.1 & 10 & Law School & Careers Centre \\
\hline Other & 0.4 & 0.6 & 11 & Other & Other \\
\hline $\mathbf{N}$ & 159.0 & 121.0 & & & \\
\hline
\end{tabular}


Table 17: Same Choice if More Information Regarding

Legal Studies?

\begin{tabular}{|lcc|}
\hline SQ 21 & SAME CHOICE IF MORE INFO ABOUT LAW STUDIES (\%) \\
\hline & First Year (\%) & Final Year (\%) \\
YES & 71.7 & 81.7 \\
NO & 5.0 & 3.3 \\
DON'T KNOW & 23.5 & 15.0 \\
$\mathbf{N}$ & $\mathbf{1 5 9 . 0}$ & $\mathbf{1 2 1 . 0}$ \\
\hline
\end{tabular}

Table 18: Same Choice if More Information Regarding Legal Career?

\begin{tabular}{|lcc|}
\hline SQ 21 & SAME CHOICE IF MORE INFO ABOUT LAW STUDIES (\%) \\
\hline & First Year (\%) & Final Year (\%) \\
YES & 74.1 & 74.4 \\
NO & 3.2 & 9.1 \\
DON'T KNOW & 22.8 & 16.5 \\
$\mathbf{N}$ & $\mathbf{1 5 8 . 0}$ & $\mathbf{1 2 1 . 0}$ \\
\hline
\end{tabular}

Finally, we have attempted to assess the adequacy of the information which students obtained concerning law as an academic discipline and as a professional career respectively. Here the questionnaire asked whether students would have made their decisions to apply for admission to law also, or again, if they had had more information about both law as a discipline and the legal career options (Tables 17 and 18). Overall, law students indicate that, retrospectively, they had sufficient information or would have made the same decision. Only very few feel that what they know now about law would have dissuaded them from applying for admission if it had been known to them then.

However, there is a substantial number of law students, especially in first year, who are not so sure. It is difficult to assess why so relatively many students express a certain uneasiness as neither correlations with academic achievement variables nor with 
family background variables return any significant differences between those students and those who are more confident that they made the right choice. However, the fact that particular students in first year are unsure about the adequacy of prior information both in relation to law studies and the legal career, and that a considerable number of older students indicate that they would not have chosen law if they had had more information earlier, seems to point again to the role which perceptions play in cognitive adjustments at the time when the students report their recall. In this sense, the response of first year students that they are unsure may mean that they experience difficulties in coming to terms with their legal subjects, ${ }^{59}$ while older students experience a crisis in relation to the question what to do after they finished their studies. So it is more likely that this current experience of difficulties rather than the recall directs their negative self-report. ${ }^{60}$

\section{Socialisation and Education the Tertiary Education Level}

\section{Tertiary Institutions other than University}

Due to the present admission practices of the University of Sydney, the great majority of law students in this law school come directly from secondary schools and so form the dominant law student sub-culture. Also the few students who enter law school as a graduate student come largely from another faculty of the University of Sydney. Even fewer law students enter law school at undergraduate level after they have come through tertiary education outside the university sector through colleges of advanced education or TAFE. Accordingly, the total number of students in our sample who have followed this career path is only under $2 \%$ and too small (Table 19) to return any meaningful quantitative results about this group of law students. 
Table 19: Type of Degree

\begin{tabular}{|lcc|}
\hline SQ3 & CAT. OF ENTRY TO LAW SCHOOL & \\
\hline \multicolumn{2}{|l}{ First Year } & Final Year \\
Comb. Law HSC & 88.7 & 59.2 \\
Comb. Law Pre & 9.4 & 5.0 \\
Tertiary Rec & & \\
S Law Graduate & & 26.7 \\
S Law HSC & 1.9 & 7.5 \\
Other & $\mathbf{1 5 9 . 0}$ & 1.7 \\
$\mathbf{N}$ & & $\mathbf{1 2 0}$ \\
\hline
\end{tabular}

SOCIALISATION AND EDUCATION AT UNIVERSITY

LEVEL

With the elimination of a direct and exclusive enrolment in the faculty of law in 1988, only very few (8\% in final year), and older, students in the law school are now not enroled in one of the combined degree courses (arts/law, economics/ law, science/law) or do not, by being admitted as graduate students, graduate from the law school with two degrees. This is, in itself, an indication of the growing intensity of the selective practices which are discussed here. The large group of students who are enroled in the combined degrees, then, sets the standards and patterns for law student socialisation experiences (89\% in first year, 59\% in final years). As observed above, most students of the relatively few students who are admitted as graduate students have attained their first degree in other faculties of the University of Sydney and rarely come from other universities in Sydney. Even less graduate students migrate to Sydney from universities outside of NSW or from overseas (Table 20). Graduate students differ from the combined law degree students in that they are older than the combined degree students and that they come from less affluent backgrounds. ${ }^{61}$ This basic difference makes them perceive differences between themselves and the combined degree students more acutely, even for the 
outside observer the differences seem to be small and insignificant.

Table 20: Entry to Institution

\begin{tabular}{|lll|}
\hline SQ 7.3 & ENTRY TO INSTITUTION & \\
\hline & First Year & Final Year \\
University of New South Wales & 71.7 & 81.7 \\
Macquarie University & 5.0 & 3.3 \\
University of Sydney & 23.3 & 15.0 \\
Other NSW University & & \\
Other Aust. University & & \\
Not Applicable & & \\
$\mathbf{N}$ & $\mathbf{1 5 9 . 0}$ & $\mathbf{1 1 9 . 0}$ \\
\hline
\end{tabular}

Such a different outlook of students who are admitted as graduates $(p=0.0000)$ is reflected in their reported reason why they chose the University of Sydney for studying law. Significantly $(\mathrm{p}=0.0000)$, by far the most important reason reported by combined law degree students is the specific a peal of Sydney University as one of the most prestigious, if not the most prestigious university in NSW (Table 21). This supports our earlier findings of the outstanding value which resourceful families place on academic education and it puts into perspective how much value is placed by law students and their parents on a wide range of traditional academic disciplines which can be combined with the studies for a law degree. The strength of the University of Sydney is seen in providing especially this wide range of academic excellence and we can suggest that it is the more concrete institutional and prestigious image of the University as a whole which appeals to the specific population of high school students and their families rather than the diffuse image of law and legal education which is of secondary concern in the choice of preferences. 
Table 21: Reasons for Studying Law at Sydney University

\begin{tabular}{|c|c|c|c|c|c|}
\hline \multicolumn{6}{|c|}{ SQ 37 PRIMARY REASON } \\
\hline & $\begin{array}{l}\text { First } \\
\text { Year } \\
(\%)\end{array}$ & $\begin{array}{c}\text { Final } \\
\text { Year } \\
\text { (5) }\end{array}$ & & $\begin{array}{l}\text { Ranking } \\
\text { First Year }\end{array}$ & $\begin{array}{l}\text { Ranking } \\
\text { Final Year }\end{array}$ \\
\hline $\begin{array}{l}\text { Prestige Law } \\
\text { School }\end{array}$ & 15.2 & 11.6 & 1 & $\begin{array}{l}\text { Prestige } \\
\text { University`}\end{array}$ & $\begin{array}{l}\text { Prestige } \\
\text { University }\end{array}$ \\
\hline $\begin{array}{l}\text { Prestige } \\
\text { University }\end{array}$ & 44.9 & 36.4 & 2 & $\begin{array}{l}\text { Sufficient } \\
\text { HSC }\end{array}$ & $\begin{array}{l}\text { Offer of } \\
\text { Place }\end{array}$ \\
\hline $\begin{array}{l}\text { Offer of } \\
\text { Place }\end{array}$ & 1.9 & 12.4 & 3 & $\begin{array}{l}\text { Prestige Law } \\
\text { School }\end{array}$ & $\begin{array}{l}\text { Prestige Law } \\
\text { School }\end{array}$ \\
\hline $\begin{array}{l}\text { Interesting } \\
\text { Curriculum }\end{array}$ & 1.3 & 0.8 & 4 & $\begin{array}{l}\text { Reputation for } \\
\text { Teaching }\end{array}$ & $\begin{array}{l}\text { Family } \\
\text { Tradition }\end{array}$ \\
\hline $\begin{array}{l}\text { Reputation } \\
\text { for Teaching }\end{array}$ & 5.7 & 5.0 & 5 & $\begin{array}{l}\text { No Particular } \\
\text { Reason }\end{array}$ & $\begin{array}{l}\text { Sufficient } \\
\text { HSC }\end{array}$ \\
\hline Convenience & 4.4 & 7.4 & 6 & $\begin{array}{l}\text { Family } \\
\text { Tradition }\end{array}$ & $\begin{array}{l}\text { No Particular } \\
\text { Reason }\end{array}$ \\
\hline $\begin{array}{l}\text { Family } \\
\text { Tradition }\end{array}$ & 4.4 & 9.9 & 7 & Convenience & Convenience \\
\hline $\begin{array}{l}\text { Sufficient } \\
\text { HSC }\end{array}$ & 17.1 & 8.3 & 8 & Offer of Place & $\begin{array}{l}\text { Reputation } \\
\text { for Teaching }\end{array}$ \\
\hline $\begin{array}{l}\text { No Particular } \\
\text { Reason }\end{array}$ & 5.1 & 8.3 & 9 & $\begin{array}{l}\text { Interesting } \\
\text { Curriculum }\end{array}$ & $\begin{array}{l}\text { Interesting } \\
\text { Curriculum }\end{array}$ \\
\hline $\mathbf{N}$ & 158.0 & 121.0 & & & \\
\hline
\end{tabular}

In contrast, graduate students are more independent from their parents, more pragmatic and place much less value on the prestige of the University (25\% versus $44 \%$ of the combined degree students). They report that the $\mathrm{m}$ fact of having been offered a place at the law school was, at least, an equally important reason far them (25\% versus $3 \%$ of the combined degree students). In addition, graduate students rank the prestige of the law school itself as a mason for studying law there slightly higher $116 \%$ versus $13 \%$ of the combined degree students) and give more clearly priority to pragmatic reasons (work hours compatible, location compatible, travelling time compatible and so on) than combined degree 
students (16\% versus $3 \%)$ in their decision to go to the Sydney University Law School. This highlights the fact that graduate students have progressed to stages in their life-careers where a number of additional concerns compete with the concern for their academic studies. Their problems in attempting to balance competing commitments in an environment which prefers to ignore such problems set them most dearly apart from the combined degree students for whom these problems are, as yet, not so acute. This observation is also supported by our qualitative analysis.

Degrees in other faculties. Though all versions of the combined degree operate under the same admission requirements, law students chose predominantly the Arts/Law combination, or an arts degree prior to the law degree in the case of graduate students (Tables 22 and 23).

Table 22: Combined Degree Type

\begin{tabular}{|lcc|}
\hline SQ 6 & WHAT FACULTY ENROLED IN & \\
\hline & First Year & Final Year \\
Arts & 48.4 & 36.7 \\
Economics & 37.6 & 27.5 \\
Science & 14.0 & 6.7 \\
Not Applicable & - & 29.2 \\
$\mathbf{N}$ & $\mathbf{1 5 7 . 0}$ & $\mathbf{1 2 9 . 0}$ \\
\hline
\end{tabular}


Table 23: Graduate Degree Type

\begin{tabular}{|lcc|}
\hline SQ7 & WHAT DEGREE HELD & \\
\hline & First Year & Final Year \\
B.A. & - & 20.2 \\
B.Sc & - & 4.2 \\
B.Ec & - & 3.4 \\
B.Eng & - & 0.8 \\
Double & - & 7.5 \\
Not Appl. & 100.0 & 68.9 \\
$\mathbf{N}$ & $\mathbf{1 5 9 . 0}$ & $\mathbf{1 1 9 . 0}$ \\
\hline
\end{tabular}

A closer examination reveals here that especially those students from resourceful families (high occupational status of father, high level of educational attainment of father and mother) - who constitute the largest group of law students in absolute numbers choose the arts/law degree combination and, to a lesser extent, the science/law degree combination while students from less resourceful families or from families who appear to be upward mobile tend to prefer the economics/law degree. This observation supports our earlier finding that access to and participation in dominant culture is not only engineered socio-economically but also socio-culturally. Here the study of arts and humanities and the combined arts/law degree may play a role, more than the study of economics and the combined economics/law degree, to classify a specific group of people who are aware of such links between university education and dominant culture and can use this link to their advantage.

Another factor in the explanation of the preference for the arts/law degree is related to gender. Women prefer significantly $(\mathrm{p}=0.0052)$ the arts/law degree (52\%) over the economics/law degree (26\%) and the science/law degree (9\%), while men, conversely, prefer the economics/law degree (42\%) over the arts/law degree (32\%) and the science/law degree (13\%). In the light of what has been said earlier about the intergenerational transmission of values through mothers rather than through fathers, 
this finding of an elective affinity between women and the dominance of the B.A. degree among women, relates both to the high incidence of mothers with this degree reported by the law students and to the prediction that the female B.A./LLB students are well positioned to become powerful communicators of the dominant culture themselves even if this is not necessarily reflected in the occupational status which they will eventually attain.

Surprisingly, the difference of the type of high school from which the law students graduate has no discernible effect on the choice of the type of the degree. ${ }^{62}$ Though it could be expected that especially the curricula of independent schools predispose students for a preference for the arts/law degree while Catholic and nonselective schools could be seen to cater predominantly for an upward mobile student population ${ }^{63}$ with a preference for economics/law degree, the data do not show such effects.

\section{Admission to Law School}

The self-reports of the law students confirm that the decision to embark on a university degree is taken relatively early in the educational plans of parents and students. In contrast, the decision to study law comes relatively late. It is this group of students with parents with a long-term commitment to a high level of educational attainment rather than with a firm preference for the particular vocational training of law who dominate the profile of Sydney University Law School students. The high demand for the combined law degree as a high educational level degree has allowed universities to peg the admission to it increasingly at the top end of selective procedures. In support of this trend, the operation of quota schemes, that is, the induction of scarcity of admission on the basis of economic student/teacher ratio calculations, has allowed universities to consolidate the status of the combined law degree as a high educational level degree. As a result, the required classification level (HSC/TER) for admission to the combined law degree has steadily increased and is reflected in the student populations in different admission years (Chart 14). Given the involved selective dynamics, pressure on the admission to the combined law degrees is set to remain high, in spite of an increase of law school places in NSW overall with the establishment of new law schools, a possible drop in average first 
year incomes of young lawyers with the saturation of the job market in the law firm and, especially the large law firm, sector and a steady increase of jobs in the public and administrative law sector. Overall, the pool of high level academic achievers will increase rather than decrease and the selectivity of the education system will intensify rather than slacken. Under these circumstances, it must be expected that the number of students seeking admission to a limited number of law school places will increase faster than the increase of law school places in coming years.

Chart 14: Entry Scores for Admission to Law School (HSC)

口irst $\square$ Final

Intake group (in \%)

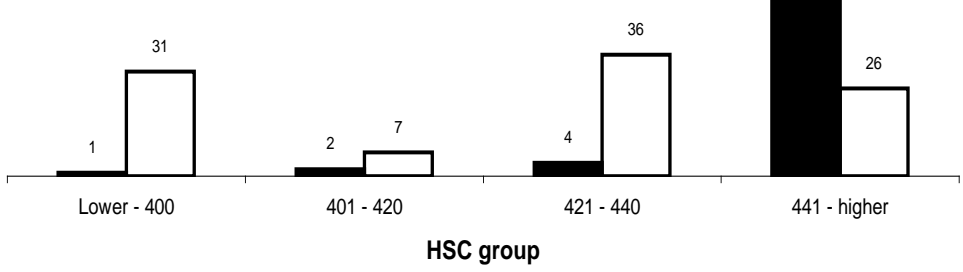

\section{WOMEN AND ADMISSION TO LAW SCHOOL}

With the intensification of the educational (selective) value of the law degree by:

1 lengthening the educational career-path to attain it by combining the law degree with other degrees, especially the arts degree, and

2 tightening the quota of admissible students by freezing supply of law school places in spite of considerable increases of demand, and so raising the level of educational attainment necessary to qualify for admission,

the proportion of women admitted to law school has increased steadily and considerably. Women form now the majority of law students. This is reflected in our samples of the law student population (first year: 51\%, final year: 57\%). 
Female law students differ very little in their personal and educational profile from male students, as far as it could be ascertained by our study. This is largely explained by the particular bias of the law student population towards highly resourceful families in which the genderised upbringing of girls is less pronounced than in less resourceful families and where there is a stronger support for the equality of opportunity for girls, especially through the significantly higher proportion of mothers in these families who have attained high levels of formal education themselves. However, even here socio-cultural valuations prevent a full realisation of equality and lead to genderised patterns of selfconcept operation by women which is different from that operated by men. Such patterns are not visible on the level of formal educational qualification if, as in our case, academic credentials are made the criteria for selection and women perform here as well or better than men; most correlations which involve indicators of formal educational attainment fail to return significant differences between female and male law students. Patterns of genderised selfconcept operation are largely communicated in more subtle forms. The result of the operation of such genderised patterns is, for instance and as shown, the preference of women for the arts/law degree. However, we must assume that such patterns operate also in many other respects such as differences between male and female students in degrees of self-confidence (but not self-esteem) and assertiveness or degrees of self-control, as informed by pervasive traditional "nice-girl” concepts. Such more subtle but nevertheless pervasive patterns would also explain our earlier finding that women rate helping as a reason to study law overall higher than men. This is not because female law students subscribe to the value of helping in a higher degree than male law students. Rather, women present themselves in their self-reports, as overall, with a differently socialised, and so genderised, response style: women are brought up to be more reluctant to reject such caritative values of a vocational career as curtly as men - qui facet consentire videtur. 


\section{FULL-TIME OR PART-TIME STUDIES AND SUPPORT DURING STUDIES}

Evidently, the majority of all law students at Sydney University Law School come directly from a selective high school and from a more or less supportive family home in one of the more affluent suburbs in the Sydney metropolitan area. Their admission to university and law school coincides for most of them with considerable changes in their life-careers: students have to learn to experience themselves as independent young adults who can take charge of their own lives. The experience of adulthood, and concomitant changes in self-concept, come earlier for young adults who are not at all or not as much committed to the value of higher education as the law students and the parents of law students. For the majority of law students, however, such changes in self-concept come comparatively late. They form then an undercurrent of coping tasks which add pressure to the work load of educational tasks during the years of study. Our data show that this pressure of everyday-life coping on students increases as the years of study pass, and that there are distinctly different patterns for first year law students and older law students in the way how this coping pressure is relieved through different arrangements of support (Table 24). While, as expected, parents are the major source of support for students who come directly from high school, this supportive role of parents diminishes as students get older or come to law school as graduate students. Here, the supportive role of parents is partially replaced by the own work in paid employment, by the increased demand on grants and scholarships but also by relying more heavily on savings.

Table 24: Primary Source of Support

\begin{tabular}{|lcc|}
\hline SQ 30 & PRIMARY SOURCE OF FINANCIAL SUPPORT \\
\hline \multicolumn{4}{|c|}{ First Year (\%) } & Final Year (\%) \\
Austudy & 7.5 & 10.3 \\
Other Scholarship & 0.6 & 0.9 \\
Parents & 52.2 & 27.4 \\
Savings & 1.3 & 2.6 \\
\hline
\end{tabular}




\begin{tabular}{|lcc|}
\hline Paid Work & 9.4 & 35.9 \\
Partner & 0.0 & 0.0 \\
Other & 28.9 & 23.1 \\
$\mathbf{N}$ & $\mathbf{1 5 9 . 0}$ & $\mathbf{1 1 7 . 0}$ \\
\hline
\end{tabular}

Though women in our law student sample are more frequently supported by parents than male students (46\% versus $37 \%$ ), and men, conversely report more frequently paid work as their primary source of support then women (men: 27\%, women: 16\%), the gender difference is not big enough to be statistically significant. Predictably, a more important difference ${ }^{64}$ is made by the occupational status of the father. Here students with fathers with upper professional status report the highest proportion of parental support (51\%) and a low, but not the lowest, proportion of paid work (19\%), students with fathers who are reported with the occupational status of a worker have the lowest proportion of parental financial support (5\%) and the highest proportion of paid work (36\%) but also by far the highest proportion of support from the Government's Austudy support grant scheme (23\%).

For all other groups of law students, Austudy grants are only a minor source for financial support. The fact that the children of fathers with managerial and entrepreneurial occupational status resort slightly less to paid (employed) work as a source of financial support than the children of fathers with upper professional status (17\% 14\% and 19\% respectively) may indicate that "full-time" law students who engage in paid work are motivated to do so also by other than purely economic considerations, such as social networking, work experience or simply diversion in a dull course of studies. On the other hand, the correlation of the HSC source of financial support shows clearly ${ }^{65}$ that students with the highest HSC results (441 and over) have predominantly parents as the source of their support (53\%), while students with the lowest HSC score (up to 401) have also the lowest degree of parental support (14\%) and the highest proportion of Austudy support (22\%). Behind the figures, we find again the uneven distribution of the entry scores between combined law degree students and graduate students. This takes here the form that the graduate, and older, law students have the lower academic credentials which prevent them 
to enter law school directly and force them to take the detour of another degree. Being now older and coming from less resourceful family backgrounds than students who come directly from high school parental support for them is much less likely than is the case for the combined law degree students.

The increasing role of paid work, in turn, competes considerably with the demands on time and attention paid by law students to their studies. A majority of all law students, and whether or not their primary source for financial sup port is paid work, report that they work during the semesters (Table 25), and that their work in paid employment increases the further they advance in their studies at the law school.

Table 25: Current Paid Work

\begin{tabular}{|lcc|}
\hline SQ 31 & CURRENTLY IN REGULAR PAID WORK & \\
\hline & First Year (\%) & Final Year (\%) \\
YES & 55.3 & 66.1 \\
NO & 44.7 & 33.9 \\
N & $\mathbf{1 5 9 . 0}$ & $\mathbf{1 2 1 . 0}$ \\
\hline
\end{tabular}

The proportion of those who report such commitments is similar for women (61\%) and for men (HI\%) and not significantly related to the occupational status of the father. Overall, more than $50 \%$ of law students in all groups manage somehow not only to combine regular paid work and university studies but also to complete their studies successfully,

The pervasiveness of this extracurricular activity is further evident by the increase of work hours which law students spend in those activities away from their studies (Table 26). The conclusion which can be drawn from these observations is that:

1 the normative claim alone that law school studies are fulltime studies does not achieve much to keep students at their books,

2 the intellectual challenge of studying at law school is not demanding enough to prevent intellectually highly competent students from taking on additional tasks without compromising the success of their studies to any significant degree, and 
the regulatory framework66 of highly repetitive and formalised law courses with a high degree of examinations as assessment form, is a sitting target for subversion by law students who, after having met the highest requirements for entry to university studies, can claim that their right for intellectual self-determination is not taken seriously enough by being subjected to surface learning.

Table 26: Work Hours

\begin{tabular}{|lcc|}
\hline SQ31.1 WORK HOURS & & \\
\hline & First Year (5) & Final Year (\%) \\
Under 5 hours & 24.1 & 3.7 \\
5-10 hours & 42.5 & 34.1 \\
10-20 hours & 28.7 & 47.6 \\
Over 20 hours & 4.6 & 14.6 \\
$\mathbf{N}$ & $\mathbf{8 7 . 0}$ & $\mathbf{8 2 . 0}$ \\
\hline
\end{tabular}

This interpretation of the survey results is further supported by the accounts which students gave about their experiences of studying law.

The clash of the occurrence of important life-events with the studies at law school is further indicated by the clear increase of household commitments of older students (compare Tables 27 and 28). Though child-care commitments do not constitute a significant problem of this student population - less than 1\% report having children - it is evident that a growing number of students establish or are committed to established living arrangements of some form or other with another person or a number of other persons away from the family home; formally, only a small number of students are married or marry at this stage of their life-careers. Law students are also reluctant to call these interpersonal relationships, where they exist, engagements or de facto marriages (Table 27). Women report a higher household commitment than men (45\% vs. 30\%) but this difference is not statistically significant. Similarly, women and men report their marital status in equal proportions (single: 91\%; married women: $4 \%$, married men: $6 \%$ ). As follows from the 
discussion above, and as predicted by family studies literature, students with fathers with the occupational status of a worker report a slightly higher marriage rate than any other group of students (13\% vs. upper professional: 4\%, upper services: 6\%, managerial: $7 \%$, entrepreneurial: 2\%). However, as far as our sample of law students is concerned, this result is not statistically significant due to the very small number of students with that family background in our sample. Furthermore, it is likely that the higher proportion of married students in the group of less resourceful families is more related to the fact, which was observed earlier, that a higher number of older students come from that background, and that it is age rather than a demonstrable inclination to marry early which produces the observed difference.

Table 27: Household-/Child Care Commitments

\begin{tabular}{|lcc|}
\hline SQ 32 & HOUSEHOLD-CHILD CARE COMMITMENTS \\
\hline & First Year (\%) & Final Year (\%) \\
YES & 29.5 & 50.4 \\
NO & 70.5 & 49.6 \\
N & $\mathbf{1 5 9 . 0}$ & $\mathbf{1 1 7 . 0}$ \\
\hline
\end{tabular}

Table 28: Work Hours Home Duties

\begin{tabular}{|lcc|}
\hline SQ 32.1 WORK HOURS & & \\
\hline & First Year (\%) & Final Year (\%) \\
Under 5 hours & 56.5 & 15.3 \\
5-10 hours & 32.6 & 61.0 \\
10-20 hours & 6.5 & 16.9 \\
Over 20 hours & 4.3 & 6.8 \\
$\mathbf{N}$ & $\mathbf{4 6 . 0}$ & $\mathbf{5 9 . 0}$ \\
\hline
\end{tabular}

Table 29: Status

SQ 33 STATUS 


\begin{tabular}{|lcc|}
\hline & First Year (\%) & Final Year (\%) \\
Single & 99.4 & 80.2 \\
Engaged & 0.0 & 4.1 \\
De Facto & 0.0 & 4.1 \\
Married & 0.6 & 11.6 \\
$\mathbf{N}$ & $\mathbf{1 5 9 . 0}$ & $\mathbf{1 2 1 . 0}$ \\
\hline
\end{tabular}

\section{THE EXPERIENCE OF STUDYING LAW}

Our in-depth interviews allow us to elaborate on the responses in the survey in relation to the conditions of studying at law school and to add the students' point of view to our interpretations. Overall, students seem to agree with the way in which work practices in the admission to law school operate, at least to the degree that they are not deterred to do everything again in the same way if they were faced with that decision again. However, such a verdict does not necessarily allow the conclusion that law school operations are perfect. Rather, it appears that above all the assessment of the quality of studying law is informed by a feeling of resigned fatalism on part of the law students.

Studying at the law school has to be endured, rather than that it can be enjoyed, as a $\mathrm{m} \mathrm{n} \mathrm{s}$ to the end of a successful, remunerative career in the legal profession. As such, the peculiar quality of studying law is tolerated as a rite of passage which constitutes only a stepping stone for the life after law school without much intrinsic value as an academic activity:

I've never really applied myself as much as I did in my honours years [in arts]. I've just tried to perfect the technique of getting reasonable marks ... I thought it was quite shallow (22 - B8).

I don't like the subject [law]. I think its emphasis on law and exceptions to that sort of thing ..on a philosophical level ... takes away from the humanity of law... Instead you get the ridiculously complicated set of laws that work out where it goes. So I think on that level I don't like the formalism $(6-\mathrm{B} 8)$.

I think here is an over-emphasis on cramming for exams ... I think that's got to be a bad thing because you forget everything so quickly when you cram for exams $(23$ - B8). 
The other strong impression I get is that [law is a difficult subject] is simply not true but is a myth which makes you feel that there is something quite behind it. Because you can get away with a minimal amount of study and I mean last year with the help of friends I did not attend class, I just read their notes and sat for the exam and got through and I am not the only one (7 - B8).

I think the biggest thing about my experience of studying law is that I had to work 2-3 days a week throughout my law degree and that made it very difficult because none of the lecturers had really time for people who have to go [to work] in the evening. So it just meant I missed a high proportion of lectures. It just made it a real hard work. And I think it's unrealistic to think that people can't and don't do it because I know people who have done law and have never gone to one lecture because they have been working full-time. So that really strikes me, the sort of the unreality of expecting people not to work and the unreality of expecting people to do it full time (8-B8).

This clash of different levels of the operation of law school practices is, as we have seen, the result of the congruence of everyday-life coping and studying which is particularly problematic for specific groups of students:

It's been like learning in a vacuum. I can't speak for undergraduates [i.e. non-graduates] here. Most graduates here hate it. We were just talking about it downstairs and most people hate and loath this law school. Well, I think there is a big difference between people who have just come from school and graduates. The problems that graduates are going to face aren't really catered for ... I don't think in the structure of the course. The chief one being financial. There's virtually no leniency or room for work for instance. They don't structure the course so that you can have a day off in the week. And if you have to work, then it is just tough ... (2-B8).

Again, the other thing about my study is that being an older student I had a lot of outside study commitments that I've to deal with and I had mixed reactions from the law school about that ... I remember going to the Dean and saying [what was] happening .... . And he was terribly sympathetic until I said on top of that I was working and then .. the shield came down and he was no longer assertive and said University had a policy that students aren't to work. And I guess I feel bitter about that still $(7-\mathrm{B} 8)$.

Nevertheless law students, being well educated and polite people, are quick to point out redeeming aspects and explanations for their experience of studying at the law school:

Some of the courses I think are a little on the dull side but you're bound to strike that for anything. Some have been good, some are well thought, some, I think perhaps I think are lacking a little. Some have been a little organised, we've been given a little run around, though it's 
not typical and I guess to some extent it can be due to all sorts of factors $(3-\mathrm{M})$.

I think one of the positive effect it had is that it made me think a little bit more logically whereas before ..it was very much sort of all English and history and stuff and law has made me sort of think a little bit more step by step ... that sort of thing. So on that level, I suppose, it has been $\operatorname{good}(6-\mathrm{M})$.

The first three years were basically a non-experience in studying law which was quite stressful. But only after when the results came back, since then I've found it very interesting as a body of theory and applied theory $(10-B 8)$.

The first few years I didn't really feel like I was studying law because I was doing my other degree mainly. I remember in legal institutions we always had materials to read and we were sort of bamboozled in the kind of language. It took us a while to get used to the style of mainly the reading material that we have to go through and also the whole process I think is somewhat different. It takes a while to get into the flow of it $(24-\mathrm{B} 8)$.

Good and bad. I found it at first very difficult to fit into the legal way of thinking, coming from arts. I suppose, I just naturally lean towards discussing rather than learning rules and being able to put them down and actually utilise them which is what law is all about. First I found that difficult. Now, I am actually seeing the way it is and I'm working with it. I quite enjoy that as well (26 - B8).

Many students, however, are quite fond of their law school experience:

It's been interesting, it drags on a little bit but it's quite interesting, different, yeah $(1-\mathrm{B} 8)$.

Generally pretty good. It has been very intensive the last of this year and last year particularly. I think to start with we saw very little of the law, particularly in the first two years, that was only a small percentage of the course I was doing and I didn't really do much law at all. Generally, it's been good (3 - B8). Well, I have really enjoyed it. Apart from the very first subject I had.. . (4 - B8).

On a wider scale, I've enjoyed most of my time here a lot. I don't like first year for the same reasons no one likes first year. But since then, I think, I am really happy with the whole social set-up and that sort of thing $(6-B)$.

I think it has given me a lot of satisfaction and it has certainly focussed the direction of the very important areas which is going to make my family life sort of more balanced. Overall, [the law school experience] would be good $(7-B)$. 
So far it's very interesting and enjoyable. I find that with the semester system the subjects are concentrated in one semester, so wk have a better grasp of what we are doing $(25-\mathrm{B} 8)$.

I enjoy it. I actually enjoy the law. For me part of the problem would be to adjust to the fact that a lot of legal practice has nothing to do with the law in the substantial sense. For me it was always an interesting and challenging subject area in itself $(28-\mathrm{B} 8)$. 


\section{EXPECTED CAREERS}

The law students who are admitted to Sydney University Law School in the particular way which has been discussed here rank the legal practice in one of the big city law firms as their preferred option for the career after graduation from law school. This option is ranked highest both by first year law students and by the more experienced students (Table 30) and by both female and male students. The gender difference noted here - women: $26 \%$ and men: $38 \%$ - is considerable but not statistically significant. Overall, the option of legal practice as a private practice could also be seen as the underlying rationale for the legal education curriculum; it is, therefore, not surprising that law students rank this career option highest.

However, also here students adjust their preferences according to their perceptions of the current situation as they progress with their studies. Older students are increasingly ranking the corporate law firm as their preferred option and abandon the idea of practicing law as a self-employed single practitioner, probably as a result of accumulating more information about the different career options. Overall, however, there is a considerable distance between the first rank of preferred legal career options (legal practice in a city law farm) and the next options (legal practice self-employed, lawyer employed by a business firm respectively) in the valuation of law students. Notably, all three top rankings refer to legal practice in the private sector. This underlines the specific way in which the operation of the legal system is perceived, taught and learned in legal education organisations which are based on the English common law tradition. ${ }^{67}$ 
Table 30. Expected Career

\begin{tabular}{|c|c|c|c|c|c|}
\hline & $\begin{array}{l}\text { First } \\
\text { Year } \\
(\%)\end{array}$ & $\begin{array}{l}\text { Final } \\
\text { Year } \\
(\%)\end{array}$ & & $\begin{array}{l}\text { anking First } \\
\text { Year }\end{array}$ & $\begin{array}{l}\text { Ranking } \\
\text { Final Year }\end{array}$ \\
\hline $\begin{array}{l}\text { Private } \\
\text { Practice, } \\
\text { SE }\end{array}$ & 35.0 & 25.8 & 1 & $\begin{array}{l}\text { Private } \\
\text { Practice, } \\
\text { Firm }\end{array}$ & $\begin{array}{l}\text { Prestige } \\
\text { University }\end{array}$ \\
\hline $\begin{array}{l}\text { Private } \\
\text { Practice, } \\
\text { Firm }\end{array}$ & 60.4 & 68.3 & 2 & $\begin{array}{l}\text { Private } \\
\text { Enterprise, } \\
\text { Firm }\end{array}$ & Offer of Place \\
\hline $\begin{array}{l}\text { Private } \\
\text { Enterprise, } \\
\text { SE }\end{array}$ & 14.0 & 14.2 & 3 & $\begin{array}{l}\text { Public } \\
\text { Practice, SE }\end{array}$ & $\begin{array}{l}\text { Prestige Law } \\
\text { School }\end{array}$ \\
\hline $\begin{array}{l}\text { Private } \\
\text { Enterprise, } \\
\text { Firm }\end{array}$ & 30.6 & 29.2 & 4 & $\begin{array}{l}\text { Public } \\
\text { Service, } \\
\text { Law }\end{array}$ & $\begin{array}{l}\text { Family } \\
\text { Tradition }\end{array}$ \\
\hline $\begin{array}{l}\text { Public } \\
\text { Service, } \\
\text { Law }\end{array}$ & 29.3 & 25.0 & 5 & $\begin{array}{l}\text { Community } \\
\text { Work }\end{array}$ & $\begin{array}{l}\text { Sufficient } \\
\text { HSC }\end{array}$ \\
\hline $\begin{array}{l}\text { Public } \\
\text { Service, } \\
\text { Non-Law }\end{array}$ & 9.6 & 13.3 & 6 & $\begin{array}{l}\text { Private } \\
\text { Enterprise, } \\
\text { SE }\end{array}$ & $\begin{array}{l}\text { No Particular } \\
\text { Reason }\end{array}$ \\
\hline $\begin{array}{l}\text { Community } \\
\text { Work }\end{array}$ & 20.4 & 21.7 & 7 & $\begin{array}{l}\text { Public } \\
\text { Service, } \\
\text { Non-Law }\end{array}$ & Convenience \\
\hline $\begin{array}{l}\text { Teaching, } \\
\text { Secondary }\end{array}$ & 5.7 & 4.2 & 8 & $\begin{array}{l}\text { Teaching, } \\
\text { Tertiary }\end{array}$ & $\begin{array}{l}\text { Reputation for } \\
\text { Teaching }\end{array}$ \\
\hline $\begin{array}{l}\text { Teaching, } \\
\text { TAFE }\end{array}$ & 2.5 & 2.5 & 9 & Other & $\begin{array}{l}\text { Interesting } \\
\text { Curriculum }\end{array}$ \\
\hline $\begin{array}{l}\text { Teaching, } \\
\text { Tertiary }\end{array}$ & 4.5 & 13.3 & 10 & No Plans & \\
\hline No Plans & 17.2 & 9.2 & 11 & $\begin{array}{l}\text { Teaching, } \\
\text { Secondary }\end{array}$ & \\
\hline Other & 13.5 & 12.5 & 12 & $\begin{array}{l}\text { Teaching, } \\
\text { TAFE }\end{array}$ & \\
\hline
\end{tabular}


Consistently with this, also the definition of community work - ranked fifth as a career option by both first year law students and older students - is seen by the law students as a form of private legal practice for a particularly deserving clientele. While a wide majority of the students do not nominate this option, a significant number of female students (30\% as against $11 \%$ male students; $p=0.0002$ ) see this field as a career option. In view of our earlier finding that female students do not support caritative values significantly more than male students, we can expect that such a clearly gendered pattern is related to a realistic perception of the female law students of their chances on the job market and so to an adjustment of their career aspirations to that perception. However, the relatively few students, including women, who have stated that helping others was a somewhat or a very important reason for them to study law, are clearly also those who rank the community service highly; we find here a strong $(\mathrm{p}=0.0000)$ positive relation between these two measurements of students' self-concepts. We must, therefore, assume that this career option is not only an adjustment of perceptions but also a consistently followed career path, particularly for female law students.

We could expect that the clear preference for private legal practice of law students is positively related to the socioeconomic status of the families from which they come. However, such an assumption is not supported by the data. They do not show any statistically significant difference in the pattern of career preferences in the different groups of students in relation to the occupational status of their fathers. A remarkable exception are the students with fathers with the occupational status of worker who report the lowest commitment to community legal work of all groups. This indicates, at least, that the socialisation at law school - but not necessarily the education there - facilitates the transmission of traditional values regarding legal career options and promotes upward mobility values in those comparatively few students from lower middle class families who manage to gain admission to law school. All these values centre around private enterprise in contrast, for instance, to the promotion of the public good through a public service career, including academic careers in 
teaching and research. A socialisation of this type in the educational environment of law schools is the legacy of the medieval constitution of (common) law as a professional enterprise rather than as a public concern.

\section{CONCLUSION}

The self-reports of the law students reveal a peculiar tension between the academic aspirations and achievements which brought students into law school, on the one side, and the reality of an academically relatively uninspiring curriculum which they find there, on the other side. This tension manifests itself in a high degree of dissatisfaction with the formal and curricular aspects of studying law and, above all, in a high degree of extracurricular activities by law students which are not only instigated by economic needs. We have tried to explain this tension as a conflict between the operations of the law school as a trade school and as an academic tertiary education organisation, with both having their different — and divergent — objectives. In this conflict, the law school has the gatekeeper function in the process of the structural coupling of the economic system, here largely the legal profession, with the education system, here largely the university. This process has tied the access to legal careers to long, and because of that, highly selective, educational and academic career-paths. This has lifted studying law to requested levels of educational attainment which are out of reach for most school leavers in NSW but a few lucky ones. As our observations have shown, and as far as law as an academic discipline is concerned, this process is not driven by any intrinsic need for or any actual improvement of the quality of education but by the intensification and differentiation of educational selection. The combined law degree is the prototypical result of such a process. The requirements for admission to this degree have ensured that the law school, and legal practice, recruit students who come, almost exclusively, from the highest achieving student population in the state. As it happens, this is also the socially most narrow selection of students in the state.

The observed processes are complex and historically, economically and culturally deeply entrenched in the society of NSW. Any attempt to unsettle or to reverse them appear to be fanciful. Not any one actor or group of actors can achieve change 
unilaterally and without getting severely hurt in the process.

The conclusion of our study must be that admission policy can only be made by political means. It must set out goals boldly, and it must promote procedures for goal-achievement on many levels. As far as admission to law school is concerned, a bench-mark will be here to give aspiring students a chance which is at least as equitable as the lottery mentioned at the beginning. The approach of a ballot, especially if modified in form of a staggered ballot which honours achievement, is not only less systematically unfair than present admission practices, it is also feasible. ${ }^{68}$ The law school, in turn, would have to re-draft its curricula, rethink the warped concept of full-time studies and set its own agenda of modern, both technical and contextual legal education rather than to ride on the back of well-established but, as far as understanding the operation of law is concerned, irrelevant arts, economics and science courses. In view of the self-reports of the law students, as canvassed in this study, also this re-thinking of the academic operations of law schools beyond admission practices would not be a bad thing.

* Sydney University Law School.

(C) 1992. (1992) 3 Legal Educ Review 155.

1 Though the author takes full and sole responsibility for the research as conducted, interpreted and presented in the following report, I gratefully acknowledge that the underlying study is a collective effort. The questionnaire for this survey was compiled and designed by Hilary Astor, Patrick Parkinson, Julie Stubbs and KA Ziegert; Research Assistant Lynne Barnes carried out the coding and processing of the data with SPSS (Statistical Package for the Social Sciences). The ethnographic interview guideline was designed by Don Rothwell and KA Ziegert, who, together with Lynne Barnes, were also responsible for conducting and recoding the interviews. Angelita Smith transcribed the many hours of narratives patiently and aptly from the tape recordings to computer readable format. The research for this study was funded by the Law Foundation of New South Wales.

2 Scientific research accepts today that the measurement of scientific "truth" or "knowledge" is the created consensus of the scientific community rather than a discovered objective reality. Compare Y Lavee \& DC Dollahite, The Linkage Between Theory and Research in Family Science (1991) 53 J Marriage \& Fam 361 , at 361 .

3 For the most recent excellent summary of the research, see D Anderson, Access to University Education in Australia 1852-1990: Changes in the Undergraduate Social Mix (1990) 33 Aust U Rev 37; for Norway and Scandinavia, see M Nordli Hansen \& E Rogg, Höyere utdanning i Norge. Rekruttering, finansiering og umfodeling (Tertiary Education in Norway. Recruitment, Budgeting and Redistribution) (1991) 32 Tidsskrift for Samfunnsosrkning 387.

4 In Australia notably the dropping of tuition fees by the Whitlam government in 1974. See Anderson, supra note 3, at 42, 43.

5 This is seen most clearly in the wake of the squeeze on government expenditure on education in Australia and other Western societies in the 1980s. See 
Anderson, supra note 3, at 44 .

6 Even societies which have targeted the value of social equality centrally in their political programs like Sweden, Poland or the USSR have had, by a number of different historical factors, surprisingly little success in varying the social mix of their university undergraduate entrants. For Sweden and (communist) Poland, see Anderson, supra note 3, at 46-47; for the USSR, see ME Ruban et al, Wandel der Arkits- und Lebensbedingungen in der Sowjetunion 1955-1980. Planziele und Ergebnisse im Spiegel sozialer Indikatoren (Social Change of the Working and Living Conditions in the USSR 1955-1980. Planned Targets and Outcomes in the Light of Social Indicators) (Frankfurt: Campus, 1983) 149.

7 Anderson, supra note 3 , at 42.

8 The equal access of women to higher education will be qualified further in the following discussion with reference to law students. For an historical account of the access of women to legal education see A Sachs \& J Hoff Wilson, Sexism and the Law. A Study of Male Beliefs and Judicial Bias (Oxford: Martin Robertson, 1978). To date, women studying at Australian law schools represent about $50 \%$ or more of the students. It is another matter that the legal profession evidently does not recruit female law graduates in the same proportions as male students and that female law students adjust their self-concepts accordingly.

9 AI Abdelrahman \& SF Morgan, Socio-economic and Institutional Correlates of Family Formation in Khartoum, 1945-75 (1987) 49 J Marriage \&. Fam 49-52; O Albornoz, Education and Development Revisited: a Sociological Perspective (1989) 4 Int Soc'y 273.

10 Here the objective was to report quickly on the ramifications of a possible change in admission policy of one particular law school (University of Sydney) based on a fairly broadly based interest of faculty in the demographic and educational profile of law students. This allowed for only a limited research exercise with respect to lead-in time and the human resources available for conducting the research notwithstanding the substantial funding by the Law Foundation of New South Wales.

11 For instance, Lavee and Dollahite state: "The goal of producing a better consensual knowledge base — not just for the sake of knowledge, but knowledge that will provide a more valid basis for intervention and action will be facilitated by an explicit reference to theory in research reports. It is theory that gives meaning to research findings, and it is theory that enables the development of systematic consensual explanation of [social] phenomena." Levee \& Dollahite, supra note 2, at 370.

12 N Luhmann, Soziale System. Grundriss einer allgemeinen Theme (Social Systems. Outline of a General Theory) (Frankfurt; Suhrkamp, 1984). Applications to socio-legal research, family studies and legal education research are discussed in KA Ziegert, The Impossible Task of Teaching Law: Legal Education in Operation (1988) 5 Tidskrift für Rättssocidogi 183.

13 The terms socialisation and education cannot be used interchangeably as they denote different things. N Luhmann, Strukturelle Defizite. Bemerkungen zur sysfernfheorefischen Analyse des Erziehungmsens (Structural Deficits. Remarks on a Systems Theory Analysis of Education) in J Oelkers et al, eds, Pädagogik, Erziehungswissenschaft und Systemtheorie, (Weinheh Beltz, 1987) 57-75; Ziegert, supra note 12 . Socialisation can be defined as the ensemble of cognitive processes of adaptation of the personal system (learning) which are operated by every individual, and only that individual, all of the time. Education, on the other hand, is the intentionalised (organised) attempt to mobilise socialisation processes for particular purposes as directly defined by the educational organisations (kindergarten, schools, universities, etc.) and indirectly defined by political organisation (religious organisations, the economic sector, state, etc.). However, such educative attempts need socialisation to work congruently in order to be successful. In this sense, education needs individuals to mobilise their socialisation processes, or in other 
words, their active participation in the organisation of education. Clearly, such a participation cannot be taken for granted. It is entirely controlled internally by the personal system of a given individual and only poorly affected (enticed, manipulated, stimulated and so on) from outside (the education system/ environment). The individual may or may not become "educated" in the process but will become definitely socialised in the process, for example, to avoid participation in educative organisation where such participation would affect the self-concept adversely, or to accept participation where it promotes the selfconcept.

14 Social structure here means everything that can be communicated interpersonally (socially) from one individual or a number of individuals to another or other individuals in such an effective way that it affects the cognitive operations of that other individual or those other individuals. Social action and organisation, in turn, are entirely and only constituted by communication.

15 This is the consensual knowledge in socialisation research. M Hansen, Sosiale utdanningsforskjeller. Hvordan er det blitt forklart? Hvordan bör de forklares? (Social Differentiation in Education. How Has it Been Explained? How Should one Explain It?) (1986) 1 Tidsskrift for Samfunnsforskning 3; CL Cappell \& RM Pipkin, The Inside Tracks. Status Distinctions in Allocations to Elite Law Schools, in PW Kingston \& LS Lewis eds, The High-Status Track. Studies of Elite Schools and Stratification (New York: State University of New York Press, 1990) 211-230; Ziegert supra note 12. However this knowledge is not at all or insufficiently reflected in the literature on the methodology of teaching. On the methodologies of teaching, see generally P Ramsden, Learning to Teach in Higher Education (London: Routledge, 1992).

16 FG Castles, The Politics of Economic Vulnerability: A Comparison of Australia and Sweden (1987) 30 Acta Sociologica 271.

17 N Luhmann, Verfassung als evolutionare Errungenschaft (The Constitution as an Evolutionary Achievement) (1990) 9 Rechtshistorisches Journal 176; KA Ziegert, Courts and the Self-Concept of Law. The Mapping of the Environment by Courts of First Instance (1992) Syd L Rev (forthcoming).

18 The most common case, as far as legal education is concerned is the issue of what is considered to be "core" or "compulsory" subjects for a law degree. In this issue legal practice, guided by economic exigencies, and advanced legal education at university, guided by academic insights, often differ. Autonomy of both systems is, generally, preserved by differentiation of the degree structure, that is a widening of the choice of courses and certificates.

19 Notably, this applies only to the (historically, English medieval) common law tradition with its strong emphasis on legal practice as a private enterprise. In European continental law, universities have been traditionally dominant in legal education, significantly with the emphasis on turning out academic lawyers, judges and (public) administrative lawyers. Ziegert, supra note 12.

20 Anderson, supra note 3.

21 Primary groups are groups for the factual arrangement of stable face-to-face relationships which facilitate interpersonal communication on an on-going basis, and only that, in turn, allows for the attainment of social skills and selfconcept formation. The definition of primary groups in traditional terms (the family as a married heterosexual couple with child/children) is irrelevant as far as socialisation is concerned.

22 PR Arnato \& G Ochiltree, Family Resources and the Development of Child Competence (1986) 48 J Marriage \& Fam 47; PR Amato, Children in Australian Families. The Growth of Competence (Sydney: Prentice Hall, 1987).

Even if childhood socialisation experiences are of fundamental importance for the structure of personal systems, the concept of socialisation presented here makes the point that adjustment (restructuring) of the personal system takes place all the time, but then only within the limits set by the historically acquired 
structures of the personal system This observation of a high degree of adaptability of even traumatised children is supported by the most recent family research. See M Kline, JR Johnston, \& JM Tschann, The Long Shadow of Marital Conflict: a Model of Children's Postdivorce Adjustment (1991) $53 \mathrm{~J}$ Marriage \& Fam 297.

24 Compare supra note 13. For example, a truant child learns (meaning, becomes socialised) to refuse education or to rebel against external attempts of manipulation.

Though it is possible to draw a classificatory distinction between private school types (so, for instance, the Australian Bureau of Statistics, Yearbook 1988 (Canberra: AGPS, 1988) 422 distinguishes Anglican, Catholic, Other) and even between different types of Catholic schools, the important structural difference is here between the (public) community school and an intentional detour from it by adherence to particularistic (undemocratic) values. The data in the following demonstrate this significant divide and its most severe impact on the political culture in NSW and Australia.

26 This eagerness on the part of faculties to certificate has not so much education in mind but economic rationalism At the same time it points to the dilemma of the structural coupling of education with the economic system: the more an educational organisation panders to economic interests (for instance, in order to attract fee-paying students, by an inflation of certification), the more it loses its autonomy. This loss of autonomy is reflected by a loss of the academic prestige which is conferred exclusively by the academic community at large (and not b the economic system). The diminishing prestige of an educational organisation, in turn, makes it lose its attraction for economic interests by the devaluation of the certificates that this organisation can issue.

It is tempting to see the faculties of medicine as in a similar situation. However, it is important to note here that the professional training of medical doctors, riding on the back of the natural sciences, is far more specialised (differentiated) than legal education which makes a direct link with the medical profession and faculties of medicine much less pronounced.

28 The following account will show that in spite of this homogeneity of the law student population differentiating processes can be observed, even if observed differences remain generally small or statistically not significant. This general finding implies also that educational attempts to certify relatively large differences in the academic attainment within this population (by specific assessment procedures and order of merits lists) are, typically, artifacts which reflect more on the educational organisation of legal education and its operators (that is, the law teachers and the specific assessment regimes of law faculties) than on the achievement of understanding specific course contents on part of the students.

Data were collected from August 1990 to October 1990.

30 The questionnaires were distributed and filled out in class during term time with a $100 \%$ return rate.

31 Here a random number (every 7th student up to 100) of students were drawn from the Registrar's record and invited by letter to participate in the study. Of the 100 students addressed, 33 volunteered to participate and were interviewed. Interviews lasted from 30 minutes to one how and were recorded on audiotape, transcribed verbatim but only partly evaluated as far as this report is concerned.

32 V \& ML Schwalbe, Parental Behaviour and Adolescent Self- Esteem (1986) 48 J Marriage \& Fam 47; P Amato, Psychological Distress and the Recall of Childhood Family Characteristics (1991) 53 J Marriage \& Fam 1011. Amato, supra note 32, at 1018.

34 J Lobdell \& D Perlman, The Intergenerational Transmission of Loneliness: a Study of College Females and Their Parents (1986) 481 Marriage \& Fam 589; Amato, supra note 32; DB Kandel, Parenting Styles, Drug Use, and Children's 
Adjustment in Families of Young Adults (1990) 521 Marriage \& Fam 183.

It is important to note that we refer, in the following, to such an accumulation of the interdependence of economic and cultural capital where we refer to "resourceful families".

Australian Bureau of Statistics, supra note 25, at 301.

38 Here it is also remarkable, and supports the argument of homogamic patterns of family constitution further, especially in families which. cope well, that the differences in the levels of educational attainment between the mothers and fathers of law students are much smaller than the differences between the educational attainment levels of men and women in the general population.

39 A measure for the relationship of access to dominant culture and high level resourcefulness in families could be the correlation between the variables of father's occupation and country of birth. Here our data show that all fathers of law students with the highest occupational status (upper professional, upper services) are reported to have been born in Australia or in countries with AngloSaxon culture. However, the proportion of fathers of law students who have been born in countries with other than Anglo-Saxon culture is so small that this result is not statistically significant.

40 With reference to this socio-cultural variable, the self-selection of law students appears to be in contrast to the self-selection of medicine students even though both groups face similarly high admission requirements and together form the pool of high academic achievers. A recent student survey in the Faculty of Medicine of the University of Sydney has found a considerably higher rate of students from non-English speaking family backgrounds than our study of law students. Furthermore, the study of medicine students has revealed frequently poor (English) language skills in students from non-English speaking backgrounds. This clear difference between the two student populations (With the same levels of high school performance) could be explained by the preference for natural science subjects (which do not link to dominant culture) by secondary school students who want to study medicine versus preference given to humanities (English, history - which link to dominant culture) by future law students. Such an explanation is supported by our findings on the choice of subjects of law students in secondary schools but also by our interviews where students frequently referred explicitly to their quandary with the choice between medicine or law in a situation where they had achieved sufficiently high secondary school results to enter either medicine or law. Eventually, law was preferred because of strong performances in English, debating, history and languages. Typically students would state: "I think because I was reasonable at debating and sort of standing up and talking that people presupposed that law and banisters in particular was the way to go [for me] ... and the fad that I didn't really want to do much else."

41 Because availability and access to information before entering law school are more complex events than the rather more objective family variables discussed earlier, recall by students here is much more likely to be biased by their current situation and the mental state of the student at the time of the survey and the interview. The results must, therefore, be interpreted with caution.

42 It can be argued further that, in fact, also non-selective schools can be shown to operate selectively through their local setting in socioeconomically segregated areas in Sydney from which their students are drawn. Here secondary schools which are situated in more affluent suburban settings have, overall, higher performance levels resulting in higher numbers of students from these public schools to be admitted to the law degree than from public schools in less affluent settings.

43 Cappell and Pipkin find in their study of admission to elite law schools in the U.S.A. that the by far most reliable predictor variable for being admitted to an elite law school is "academic credentials", that is, educational classification. 
Cappell \& Pipkin, supra note 15. This corresponds, on a nation-wide level, to the state-wide operation of a tertiary entry score in N.S.W., that is, in the U.S and here a measurement of institutional selection practices and only in relation to that a measurement of individual achievement.

The rates for graduate students from selective state schools, Catholic schools and independent schools are $16 \%, 13 \%$ and $4 \%$ respectively.

45 Calculations in order to obtain three groups of fairly similar size are based on the 1986 ABS census data which provide an account of income per individual per suburb. The socio-economic level of a suburb was classified "low", "medium", and "high" when the percentage of incomes of $\$ 36,000$ and above per individual were up to $0.8 \%$, between $0.9 \%$ and $4.6 \%$, and over $4.6 \%$ respectively.

46 Residency was reported through postal code only. Where postal code areas and ABS local areas did not match, researchers used their local knowledge to classify the socio-economic status of the residential am.

These measurements are significant for mothers (chi-square 32.26, p) but not for fathers.

48 Chi square 35.61, $\mathrm{p}=0.0012$

49 An intriguing finding is hem also that only "Modern History" is significantly $(p=0.0003)$ more frequently chosen by students who lived in the socioeconomically less affluent suburbs of Sydney when they were in year 12; all other subjects appear to be taken proportionately to the same extent by all groups of students. No apparent explanation could be found for this observation.

50 For similarities between the profiles of law students and medicine students respectively, compare supra note 40.

51 Also here recall is evidently problematic and informed by the current situation at the time of the survey: the importance of the reason "sufficient marks" fades from memory with the final year students and so becomes less prominent in their ranking of reasons for studying law, while "employment" moves up in importance with them, which is less important for those students who have just started law school. Only 3 out of 273 students (1\%) nominated this category (compare Table 21).

$5310 \%$ of the women, but $24 \%$ of the men find this reason not at all important, $13 \%$ and $29 \%$ of the women find it of little importance and important respectively ( $10 \%$ and $33 \%$ of the men respectively). However, the few students, women included, who find "helping" an important or very important reason to study law, are particularly committed to this value and would choose community service also as a legal career option.

54 These measurements are statistically highly significant ( $\mathrm{p}=0.0002)$.

55 High income not at all important: non-selective state schools $-16 \%$, Catholic - 9\%, independent - 21\%; important: non-selective state - $35 \%$, Catholic - 42\%, independent $-36 \%$; somewhat important: non-selective state $-24 \%$, Catholic - 28\%, independent - 21\%. In contrast to Sydney University Law School, where Catholic students are overrepresented and a consistently growing group over the last decade, Catholic students are underrepresented in the admission to U.S. elite law schools. Cappell \& Pipkin, supra note 15. See also the small appeal of the particular law school and no appeal of the law school curriculum in the ranking of reasons why the law students chose the University of Sydney for their studies (compare Table 21).

57 KA Ziegert, Legal Impact in Australia and Sweden: The Diffuse Law Concept, paper presented at the 25th Annual Meeting of the Law and Society Association, Madison, Wisconsin, 1989.

58 Statistically, this measurement is moderately significant $(\mathrm{p}=0.0205)$.

59 This is above all reflected in our interviews with the final year students who report almost unanimously that the first year of their law study was the most 
difficult for them

Amato, supra note 32.

61 The correlation between the type of the degree and the socio-economic level of the residential area where students lived in the last year of high school (year 12) shows significantly ( $=0.0005$ ) that $82 \%$ and $84 \%$ of those students who lived in residential areas with a high or medium socio-economic level but only $60 \%$ of students who lived in a residential area with low socio-economic level were enrolled in one of the combined degree courses. Conversely, $15 \%$ here were enrolled in a graduate law course while only $7 \%$ and $8 \%$ of the students who lived in a residential area with medium and high socio- economic level respectively were admitted as graduate students.

62 Neither has the type of school any effect on the gender distribution which then could affect the choice of degree type, for instance, in the form that a majority of women comes through independent schools and enrol in the arts/law degree. Though the proportion of women per type of high school is biased towards less costly (meaning. less selective) education for women compared with males, however this difference is not statistically significant. In both cases most students come from independent schools (36\% female and $46 \%$ male) and least likely from non-selective schools (24\% female and 19\% male), with Catholic schools, as usual, in a middle position (24\% female and $25 \%$ male).

63 We can assume this on the basis of the observation that, as far as selective schools are concerned, most law students who report the occupational status of their fathers as workers, have graduated from Catholic schools (35\%). However, there are more law students with a father reported as worker who come from non-selective (public) schools (44\%). Conversely, only $20 \%$ of law students with fathers with upper professional status come from Catholic schools, while $54 \%$ come from independent schools and only $16 \%$ come from nonselective schools.

This difference is significant on the $\mathrm{p}$ level.

65 This correlation is highly significant $(\mathrm{p}=0.0000)$.

66 These are the normative prescription of a large number of compulsory subjects, the sequence in which the compulsory subjects must be taken. and of an upper limit of the number of units which students are allowed to take per year. This regulatory framework masquerading as educative prerequisites, is constituted by work practices which protect the law school organisation and staff from any pressure of internal competition and rapid change.

67 This is in clear contrast to the legal education in continental European legal systems which primarily qualify students to judicial and public service, including academic careers. Students' career choices are here reversed, with the public service career as the most preferred choice and the private legal practice as a less preferred option.

68 WKB Hofstee, The Case for Compromise in Educational Selection and Grading, in SB Anderson \& JS Helmick eds, On Educational Testing (San Francisco: Josey Bass, 1983) 109. 